\title{
Sex- and Estrus-Dependent Differences in Rat Basolateral Amygdala
}

\author{
Shannon R. Blume, ${ }^{1}$ Mari Freedberg, ${ }^{1}$ Jaime E. Vantrease, ${ }^{1}$ Ronny Chan, ${ }^{1}$ Mallika Padival, ${ }^{1}$ Matthew J. Record, ${ }^{1}$ \\ M. Regina DeJoseph, ${ }^{2}$ Janice H. Urban, ${ }^{2}$ and J. Amiel Rosenkranz ${ }^{1}$ \\ Departments of ${ }^{1}$ Cellular and Molecular Pharmacology and ${ }^{2}$ Physiology and Biophysics, The Chicago Medical School, Rosalind Franklin University, \\ North Chicago, Illinois 60064
}

\begin{abstract}
Depression and anxiety are diagnosed almost twice as often in women, and the symptomology differs in men and women and is sensitive to sex hormones. The basolateral amygdala (BLA) contributes to emotion-related behaviors that differ between males and females and across the reproductive cycle. This hints at sex- or estrus-dependent features of BLA function, about which very little is known. The purpose of this study was to test whether there are sex differences or estrous cyclicity in rat BLA physiology and to determine their mechanistic correlates. We found substantial sex differences in the activity of neurons in lateral nuclei (LAT) and basal nuclei (BA) of the BLA that were associated with greater excitatory synaptic input in females. We also found strong differences in the activity of LAT and BA neurons across the estrous cycle. These differences were associated with a shift in the inhibition-excitation balance such that LAT had relatively greater inhibition during proestrus which paralleled more rapid cued fear extinction. In contrast, BA had relatively greater inhibition during diestrus that paralleled more rapid contextual fear extinction. These results are the first to demonstrate sex differences in BLA neuronal activity and the impact of estrous cyclicity on these measures. The shift between LAT and BA predominance across the estrous cycle provides a simple construct for understanding the effects of the estrous cycle on BLA-dependent behaviors. These results provide a novel framework to understand the cyclicity of emotional memory and highlight the importance of considering ovarian cycle when studying the BLA of females.
\end{abstract}

Key words: amygdala; electrophysiology; estrous; fear extinction; female

\section{Significance Statement}

There are differences in emotional responses and many psychiatric symptoms between males and females. This may point to sex differences in limbic brain regions. Here we demonstrate sex differences in neuronal activity in one key limbic region, the basolateral amygdala (BLA), whose activity fluctuates across the estrous cycle due to a shift in the balance of inhibition and excitation across two BLA regions, the lateral and basal nuclei. By uncovering this push-pull shift between lateral and basal nuclei, these results help to explain disparate findings about the effects of biological sex and estrous cyclicity on emotion and provide a framework for understanding fluctuations in emotional memory and psychiatric symptoms.

\section{Introduction}

There are sex differences in the symptomology of affective disorders (Frank et al., 1988; Silverstein, 1999; Kornstein et al., 2000;

Received March 20, 2017; revised Sept. 18, 2017; accepted Sept. 19, 2017.

Author contributions:S.R.B., J.H.U., and J.A.R. designed research;S.R.B., M.F., J.E.V., R.C., M.P., M.R.D., and J.A.R. performed research; S.R.B., M.P., M.J.R., J.H.U., and J.A.R. analyzed data; S.R.B., J.H.U., and J.A.R. wrote the paper.

Grant support was provided by National Institutes of Health Grants R01-MH-084970 (to J.A.R.) and R01-MH100536 (to J.H.U. and J.A.R.). The funding agency had no role in the preparation or submission of this manuscript. We thank Dr. Lise Eliot for valuable discussion and critical review, and Brittany Avonts for assistance with estrous charting.

The authors declare no competing financial interests.

Correspondence should be addressed to Dr. J. Amiel Rosenkranz, Department of Cellular and Molecular Pharmacology, The Chicago Medical School, Rosalind Franklin University, 3333 Green Bay Road, North Chicago, IL 60064. E-mail: amiel.rosenkranz@rosalindfranklin.edu.

S.R. Blume's present address: Anesthesia Research Division, Department of Anesthesiology and Critical Care Medicine, Children's Hospital of Philadelphia Research Institute, Philadelphia, PA 19104.
Scheibe et al., 2003), and there are genetic psychiatric risk factors that are sensitive to sex hormones (Mercer et al., 2016). There is also evidence of sex differences in memory for emotional events (Canli et al., 2002; Cahill et al., 2004; Andreano and Cahill, 2009; Milad et al., 2010). While sociocultural factors shape emotion expression, sex differences in the function of the amygdala may also contribute to sex differences in emotion. Indeed, sex differences have been reported in amygdala activation patterns and laterality (Cahill et al., 2004; Goldstein et al., 2005a), and even functional connectivity between limbic structures (Hill et al., 2014), but it has proven difficult to assess the neurobiological underpinnings of these sex-related differences. Studies in rodents 
can uncover factors that contribute to sex differences and may shed light on the effects of ovarian cycle on amygdala function (Zeidan et al., 2011). Within the posterior medial amygdala, a region that contributes to social and sexual behaviors, there are robust sex differences including lateralized prepubertal differences in neuron number, excitatory synaptic input, and dendritic morphology (Cooke and Woolley, 2005, 2009; Cooke et al., 2007), postpubertal differences in soma size and morphology (Rasia-Filho et al., 2004; Cooke, 2006), and sensitivity to sex hormones (Nabekura et al., 1986; Schiess et al., 1988). In parallel, the medial amygdala is a key site for the effects of sex hormones on divergent social and sexual behaviors (Cooke et al., 2003; Cooke, 2006). However, much less is known about other amygdala regions in females that contribute to emotional memory. One key region, the basolateral amygdala (BLA), has several nuclei, including the lateral nuclei (LAT) and basal nuclei (BA), that have complementary but distinct roles in emotion-related behaviors and memory. Sex differences exist in the expression of behaviors that are sensitive to LAT and BA activity, such as less anxiety-like behavior of females in the elevated plus maze (Johnston and File, 1991; Marcondes et al., 2001), less contextual fear conditioning (Maren et al., 1994), but faster cued aversive eyeblink conditioning (Wood and Shors, 1998). This hints toward sex differences in BLA function. While sex differences in affective behaviors can differ in rodents and humans (Eliot and Richardson, 2016), a better understanding of the neuroscience of sex differences has important consequences for the interpretation of basic research and can produce hypotheses that are testable in humans.

BLA-dependent behaviors oscillate across the ovarian cycle in humans and rats (Markus, 1997; Goldstein et al., 2005b; Protopopescu et al., 2005; Milad et al., 2009). These BLA-dependent behaviors are influenced by sex hormones, such as estradiol (Gupta et al., 2001), which also modulates synaptic transmission in the BLA (Womble et al., 2002). This suggests that the ovarian cycle modulates BLA function, but this is poorly understood.

The purpose of this study was to determine whether there are sex differences in BLA neuronal activity, and whether BLA activity shifts with the estrous cycle of intact female rats. This was assessed by in vivo extracellular recordings from anesthetized rats. BLA neuronal activity is driven by excitatory glutamatergic input and regulated by GABAergic inhibition. Therefore, we tested whether glutamatergic drive and GABAergic regulation can mechanistically explain sex differences and differences across the estrous cycle by examination of anatomical correlates, in vitro electrophysiological measures of synaptic activity, and in vivo sensitivity of LAT and BA neuronal firing to glutamate and GABA.

In addition, the LAT is important in cued fear conditioning, and the BA is heavily involved in contextual fear conditioning (Calandreau et al., 2005; Onishi and Xavier, 2010; Orsini et al., 2011; Vlachos et al., 2011). To test whether shifts of neuronal activity parallel shifts in LAT and BA function across the estrous cycle, we measured cued and contextual fear behaviors that reflect the function of LAT or BA nuclei.

\section{Materials and Methods}

All experimental procedures were performed in accordance with the National Institutes of Health Guide for the Care and Use of Laboratory Animals and were approved by the Institutional Animal Care and Use Committee at Rosalind Franklin University of Medicine and Science. Measures were taken to reduce the number of animals used and to minimize distress.
Animals and determination of estrous cyclicity

Adult female and male Sprague Dawley rats (Charles River; http://www. criver.com/products-services/basic-research/find-a-model/spraguedawley-rat) were group housed (three rats/cage) with food and water available ad libitum. The animal housing room was maintained on a $12 \mathrm{~h}$ reverse light/dark cycle within a limited temperature range $\left(68-79^{\circ} \mathrm{F}\right)$ and humidity range $(30-70 \%)$. Rats were allowed 1 week to habituate to the animal facility. Following 1 week of habituation, vaginal lavages were performed on female rats, and cell cytology from samples was examined under a microscope to monitor their estrous cycles as previously described (Becker et al., 2005). Male rats were handled in a similar manner and for a similar amount of time to control for daily handling of the females. The female estrous cycle was monitored daily and followed a 4-day cycle pattern ( $2 \mathrm{~d}$ of diestrus, $1 \mathrm{~d}$ of proestrus, $1 \mathrm{~d}$ of estrus). Females with inconsistent estrous cycles were not included for these experiments. After 2 weeks of consistent and consecutive estrous cycles, females were selected based on their estrous cycle phase. Experiments were planned using females in either diestrus (low estrogen) or proestrus (high estrogen). The postnatal age of rats at experimental measurement averaged $77 \mathrm{~d}$ in females and $76 \mathrm{~d}$ in males. When possible, in vitro studies were performed with the experimenter blind to sex and estrous cycle stage, and in vivo studies were performed with the experimenter blind to estrous state.

\section{In vivo extracellular recording}

Single-unit recordings. Animals were anesthetized with urethane (1.5-2.0 g/kg, i.p.; Sigma-Aldrich) and placed in a stereotaxic device (David Kopf Instruments). The level of anesthesia was confirmed and repeatedly checked by testing the hindlimb reflex. Body temperature was monitored with a rectal temperature probe and was maintained at $\sim 37^{\circ} \mathrm{C}$ with a heating pad (model TC-1000, CWE). Before surgery, the rat was injected with a local anesthetic above the skull $(0.2-0.3 \mathrm{ml}$, s.c., $1 \%$ lidocaine, Webster Veterinary Supply). After $5 \mathrm{~min}$, incisions were made to expose the skull, and burr holes were drilled over the BLA and mPFC of the right hemisphere. Coordinates for these regions were determined using a stereotaxic atlas (Paxinos and Watson, 1998) as follows (in mm): BLA, -4.8 to -5.6 lateral, -2.8 to -3.8 caudal from the bregma landmark on the skull and 6.5-9.0 ventral; mPFC, +2.7 rostral, -0.7 lateral, and -3.7 ventral. A bipolar concentric electrode (David Kopf Instruments) was slowly lowered into the mPFC. The mPFC electrode was used to monitor the level of anesthesia with electroencephalography-like recordings of cortical local field potentials. Rats were considered to be deeply anesthetized when the primary component of local oscillations was between 0.5 and $1.0 \mathrm{~Hz}$. Electrophysiological recordings were started no earlier than $1 \mathrm{~h}$ after the completion of surgery and bipolar electrode placement. Single-barrel electrodes (2.0 mm outer diameter; World Precision Instruments) were made using a vertical microelectrode puller (PE-2, Narishige International) and were broken under a microscope to a tip diameter of $1-2 \mu \mathrm{m}$ and filled with $2 \%$ Pontamine Sky Blue in $2 \mathrm{M} \mathrm{NaCl}$. The recording electrode was lowered into the BLA using a hydraulic micromanipulator (model 640, David Kopf Instruments). To ensure similar sampling across animals, electrode penetrations through the BLA followed a predetermined grid of coordinates. Signals from the recording electrode were amplified (model 1800, A-M Systems) and filtered at 0.1 $\mathrm{Hz}$ (low frequency) and $5 \mathrm{kHz}$ (high frequency). During electrophysiological recordings, a digital oscilloscope (model 2530, B \& K Precision) and audio monitor (model AM10, Grass Technologies) were used to monitor signals. Signals were digitized through an interface (ITC-18, Heka Elektronik) to Axograph X software (version 1.3.5, Axograph Scientific) on a Mac Pro computer (Apple). Data were stored on the computer and an external hard drive for off-line analysis.

Glutamate and GABA iontophoresis. Multibarrel glass electrodes (four barrels; A-M Systems) were made using a vertical microelectrode puller (model PE-2; Narishige), and the tips were broken under microscopic control. Each barrel contained a different solution. The recording barrel was filled with a $2 \%$ Pontamine Sky Blue solution in $2 \mathrm{M} \mathrm{NaCl}$, and the other barrels were filled with $2 \mathrm{M} \mathrm{NaCl}$ for automatic current balancing, $100 \mathrm{~mm}$ glutamate, or $10 \mathrm{~mm}$ GABA. Drugs were applied by increasing the current via an iontophoresis unit (model E104B, Fintronics). 
Histology for in vivo recordings. Recording and bipolar electrode sites were verified histologically. At the end of electrophysiological recordings, Pontamine Sky Blue was iontophoretically ejected from the recording electrode to mark the recording site. A constant current of $-30.0 \mu \mathrm{A}$ was passed through the recording electrode for a minimum of $20 \mathrm{~min}$. Bipolar electrode placement was marked with iron deposits by applying 3 stimulation pulses (1.0 mA, $10 \mathrm{~s}$ duration) as previously described (Floresco and Grace, 2003). Immediately following the current injections, rats were decapitated and their brains removed. Brains were stored in $4 \%$ paraformaldehyde with $0.05 \%$ potassium ferrocyanide in $0.1 \mathrm{~m}$ phosphate buffer for $12 \mathrm{~h}$ and then stored in $25 \%$ sucrose in $0.1 \mathrm{M}$ phosphate buffer until sectioning. Brains were cut into $60 \mu \mathrm{m}$ sections using a freezing microtome (Leica Microsystems) and then Nissl stained. Recording sites were verified by light microscopy and reconstructed using a rat brain atlas (Paxinos and Watson, 1998).

\section{In vitro whole-cell recordings}

Animals were anesthetized $(90 \mathrm{mg} / \mathrm{kg}$ ketamine and $10 \mathrm{mg} / \mathrm{kg}$ xylazine, Webster Veterinary Supply) and transcardially perfused using ice-cold, aerated $\left(95 / 5 \% \mathrm{O}_{2} / \mathrm{CO}_{2}\right)$, high-sucrose artificial CSF (ACSF). The ASCF contained the following (in mM): $2.5 \mathrm{KCl}, 1.25 \mathrm{NaH}_{2} \mathrm{PO}_{4}, 25 \mathrm{NaHCO}_{3}$, 7 dextrose, $7 \mathrm{MgCl}_{2}$, and $0.5 \mathrm{CaCl}_{2}$ (from Thermo Fisher Scientific); 1.3 ascorbic acid, 210 sucrose, and 3 sodium pyruvate (from Sigma-Aldrich); and had an osmolality of $\sim 300 \mathrm{mOsm}$. After perfusion, the animal was decapitated and the brain rapidly removed. Horizontal brain slices were obtained at $300 \mu \mathrm{m}$ on a vibratome (VT1000, Ted Pella) in ice-cold high-sucrose ACSF. Brain slices were placed in physiological extracellular $\operatorname{ACSF}\left(34^{\circ} \mathrm{C}\right)$ containing the following (in $\mathrm{mm}$ ): $2.5 \mathrm{KCl}, 125 \mathrm{NaCl}, 1.25$ $\mathrm{NaH}_{2} \mathrm{PO}_{4}, 25 \mathrm{NaHCO}_{3}, 10$ dextrose, $1 \mathrm{MgCl}_{2}, 2 \mathrm{CaCl}_{2}, 1.3$ ascorbic acid, and 3 sodium pyruvate for at least $1 \mathrm{~h}$ before recording. The recording chamber was continuously perfused with the same physiological extracellular ACSF, less the ascorbic acid and sodium pyruvate. Temperature throughout the recording was maintained at $32-34^{\circ} \mathrm{C}$. Electrodes $(1.6-6$ $\mathrm{M} \Omega$ open tip resistance) were filled with an intracellular solution containing the following (in mM): $150 \mathrm{CsCl}, 0.2 \mathrm{EGTA}, 10 \mathrm{HEPES}, 2 \mathrm{NaCl}, 4$ ATP-Mg, 0.3 GTP-Tris, and 7 tris-phosphocreatine (Sigma-Aldrich); 5 QX314 chloride (Ascent Scientific); and 0.2\% neurobiotin (Vector Laboratories). Whole-cell voltage-clamp recordings were performed from visually identified pyramidal neurons within the BLA, held between -70 and $-80 \mathrm{mV}$. Only neurons that displayed $<10 \%$ change across the entire experiment in the current required to maintain the holding potential were included in the analysis. Recordings were performed using an Axopatch 200B Amplifier or an Axoclamp 2A Amplifier (Molecular Devices). Signals were low-pass filtered at $3-5 \mathrm{kHz}$ and digitized at $10-50 \mathrm{kHz}$. All electrophysiology data were recorded, stored on a computer (Mac Pro, Apple), monitored on-line, and analyzed off-line with AxoGraph X software (AxoGraph Scientific).

Synaptic currents. To isolate EPSCs, $\mathrm{GABA}_{\mathrm{A}}$ receptors were blocked with (+)-bicuculline $(10 \mu \mathrm{M}$, dissolved in dimethyl sulfoxide; Ascent Scientific), and picrotoxin (10 $\mu \mathrm{M}$, dissolved in ethanol; Tocris Cookson) was added to the ACSF. The sodium channel blocker tetrodotoxin citrate (TTX; $1 \mu \mathrm{M}$, dissolved in $\mathrm{H}_{2} \mathrm{O}$; Ascent Scientific) was added to pharmacologically isolate miniature EPSCs (mEPSCs). At the conclusion of experiments, 6-cyano-7-nitroquinoxaline-2,3-dione (CNQX; $10 \mu \mathrm{M}$, dissolved in $\mathrm{H}_{2} \mathrm{O}$; Tocris Cookson) was added to block AMPA receptors (AMPARs) and to confirm the glutamatergic nature of the events. Final total solvent concentration in the ACSF was $<0.1 \%$ of the total volume.

To isolate spontaneous IPSCs (sIPSCs), CNQX (10 $\mu \mathrm{M})$ was added to the ACSF to block AMPARs, and AP-5 (50 $\mu$ m; Tocris Cookson; dissolved in equimolar $\mathrm{NaOH}$ ) was added to block NMDA receptors. TTX $(1 \mu \mathrm{M})$ was added to pharmacologically isolate miniature IPSCs (mIPSCs). At the conclusion of experiments, (+)-bicuculline $(10 \mu \mathrm{M})$ and picrotoxin $(10 \mu \mathrm{M})$ were added to the bath to confirm the GABAergic nature of the events. Final solvent concentration in the ACSF was $<0.1 \%$ of the total volume.

Histology for in vitro recordings. After recordings, slices were fixed in $4 \%$ paraformaldehyde in $0.1 \mathrm{M}$ PBS for up to 2 weeks at $4^{\circ} \mathrm{C}$. Sections were rinsed several times with PBS, treated with $1 \%$ Triton X-100 in PBS (VWR International) for $6-8 \mathrm{~h}$ and then incubated overnight in the
Vectastain ABC Reagent (Vector Laboratories) in PBS at room temperature. After three rinses with PBS, they were reacted with diaminobenzidine (DAB) and $\mathrm{H}_{2} \mathrm{O}_{2}$ (Peroxidase Substrate Kit DAB, Vector Laboratories) in water to visualize the neurobiotin-filled neurons. Slices were washed in PBS to stop the reaction. Sections were then mounted and dried, and coverslips were applied. This was used to localize the recording sites, verified by the position of the filled neurons. Neurons were considered BLA pyramidal neurons if they were histologically confirmed to lie within the BLA and had a morphology consistent with pyramidal neurons.

\section{Golgi-Cox staining of BLA neurons}

Brains were rapidly removed, and coronal blocks containing the entire BLA were placed into Golgi impregnation solution (FD Rapid GolgiStain Kit, FD NeuroTechnologies). Throughout the processing, brains were stored in containers protected from light. Brain tissue was processed for Golgi-Cox staining according to a manufacturer-recommended protocol (FD Rapid GolgiStain Kit, FD NeuroTechnologies). Brain slices (100 $\mu \mathrm{m}$ thickness; SM $2000 \mathrm{R}$ Microtome, Leica) were collected into $20 \%$ sucrose in $0.1 \mathrm{~m}$ phosphate buffer, $\mathrm{pH} 7.4$, at room temperature. Slices were mounted on gelatinized slides and allowed to dry (25 min to $1 \mathrm{~h}$ ), then were rinsed in double-distilled $\mathrm{H}_{2} \mathrm{O}$ (two times, 4 min each rinse). Slides were dehydrated in a graded series of ethanol washes $(50 \%$, $75 \%, 95 \%$, and 100\%) and cleared with xylene. Coverslips were applied with Permount and allowed to dry.

\section{Parvalbumin immunohistochemistry}

Animals were deeply anesthetized with pentobarbital (50 mg/kg, i.p.) and transcardially perfused with vascular buffer and paraformaldehyde. Sections through the BLA of male and female rats were cut on a vibratome $(40 \mu \mathrm{M})$ and processed for parvalbumin (PV) immunoreactivity as previously reported (Rostkowski et al., 2009). Free-floating sections were blocked for $3 \mathrm{~h}$ in $5 \%$ normal donkey serum (NDS) in parvalbumin (PBS) gelatin and then incubated for $48 \mathrm{~h}$ with polyclonal PV primary antibody (1:10,000; PV anti-goat; catalog \#PV 25, SWANT; RRID: AB_10000344), 4\% NDS, and PBS-gelatin. Sections were rinsed in PBSgelatin and incubated with Alexa Fluor-488 secondary antibody (1:250; donkey anti-goat; catalog \#705-546-147, Jackson ImmunoResearch) in PBS-gelatin for $3 \mathrm{~h}$. After washes in Tris-buffered saline, $\mathrm{pH} 7.5$, sections were mounted on gelatin-subbed slides and air dried. Coverslips were applied using polyvinyl alcohol-1,4-diazabicyclo[2.2.2] octane.

Brain sections were selected from each animal based on anatomical features of the BLA and surrounding areas to match predetermined bregma levels $(-2.3,-2.56,-2.8,-3.14,-3.3,-3.6$, and $-3.8 \mathrm{~mm}$; Paxinos and Watson, 1998) and to ensure similar sampling across groups. Seven images per animal were acquired with epifluorescence microscopy and imported into NIS Elements (Nikon Instruments) for the determination of cell counts. Microscopy and software settings were equivalent for all sections and were processed together. For each image, the LAT and BA were identified and the total number of cells in the LA and BA was counted unilaterally throughout the rostral-caudal aspect of the BLA. The specificity of the signal was assessed by eliminating either the primary or secondary antibodies; further characterization of antibody specificity was previously described (Rostkowski et al., 2009).

\section{Confirmation of estrous phase}

Immediately after decapitation and brain removal, a visual inspection of the uterine horns was performed in all females as a secondary measure to confirm the estrous cycle phase (Becker et al., 2005). To further validate our assessment of estrous cycle stage, trunk blood was collected from a subset of females during the decapitation process. Blood samples were immediately centrifuged, and the plasma collected and stored at $-80^{\circ} \mathrm{C}$ until quantification of estradiol levels using an estradiol radioimmunoassay kit (sensitivity to $8 \mathrm{pg} / \mathrm{ml}$; Coat-A-Count Estradiol Kit, SiemensMedical Solutions USA).

\section{Behavioral measures}

Behavioral measures were obtained in a separate group of rats that were not used for other measures.

Cued fear conditioning. Cued fear conditioning was performed as described previously (Zhang and Rosenkranz, 2013). Conditioning and 
extinction testing were performed $4 \mathrm{~d}$ apart such that the rat was in the same estrous phase during both sessions. Conditioning was conducted in chambers enclosed in sound-attenuating cabinets (Ugo Basile), with an audio speaker (Ugo Basile), a dim house light, an infrared LED light, and a ceiling-mounted infrared-sensitive digital camera (Fire-i, Unibrain) in the cabinets. Conditioning consisted of $2 \mathrm{~min}$ habituation followed by five pairings of a neutral tone $(10 \mathrm{~s}, 1500 \mathrm{~Hz}, 85 \mathrm{~dB})$ and a coterminating footshock $(1 \mathrm{~s}, 0.3-0.5 \mathrm{~mA})$. Conditioning trials were presented at $60 \mathrm{~s}$ intertrial intervals. Rats remained in the chamber for $1 \mathrm{~min}$ after the end of the last conditioning trial and then were returned to their home cage. Four days later, conditioned freezing and within-session acquisition of extinction were tested in a contextually distinct chamber (different wall pattern and color, odors, and flooring) to minimize contextual freezing. Testing consisted of a $2 \mathrm{~min}$ habituation followed by 15 trials of tone presentation $(20 \mathrm{~s}, 1500 \mathrm{~Hz}, 85 \mathrm{~dB})$ at a $60 \mathrm{~s}$ intertrial interval. No footshock was presented during testing trials. After testing, animals were returned to their home cage. Data were collected by a computer (E6500, Dell) running video-tracking software (ANY-maze software, Stoelting) that detects and records freezing behavior.

Contextual fear conditioning. Contextual conditioning and withinsession acquisition of extinction were performed $4 \mathrm{~d}$ apart, during the same phase of the estrous cycle. The contextual fear conditioning and testing followed the same procedure as the cued fear conditioning and testing, except that testing was performed in the same chamber as the conditioning and no tones were presented.

Active avoidance. Rats were placed in an active avoidance chamber with a short divider down the center and a camera mounted overhead (model C525 HD Webcam, Logitech) and given a 5 min habituation period. Training was performed by presenting a tone $(10 \mathrm{~s}, 1 \mathrm{kHz})$ followed by a mild escapable footshock $(0.3 \mathrm{~mA})$. The footshock terminated upon movement to the other side of the chamber. This was repeated for 30 trials, with $120 \mathrm{~s}$ intertrial interval over 3 consecutive days or until criteria were reached (at least three avoidance responses over five consecutive trials). Avoidance was scored when the rat moved to the other side of the chamber during the tone. Escape was scored when the rat moved to the other side of the chamber in response to footshock. Rats were tested for extinction $4 \mathrm{~d}$ after the first day of training. This comprised a 5 min habituation period followed by 30 trials of $10 \mathrm{~s}$ tones, with a 60 s intertrial interval, in the absence of footshock. Data were collected by a computer (E6500, Dell) running software (ANY-maze software, Stoelting) to track the movement and position of the rat.

\section{Experimental design}

In vivo electrophysiology. The anesthesia depth of the animal was monitored throughout the recording by measurement of cortical local field potentials. Spectral analysis of oscillatory activity in the cortex was performed (Axograph X), and cells recorded when the peak oscillatory frequency was outside a range of $0.5-1.0 \mathrm{~Hz}$ were not included in the data analysis. Recorded neurons were included in analyses if they were located within the BLA and if the measured action potentials had a signal-tonoise ratio of at least $3: 1$. Cells also were required to have a stable $10 \mathrm{~min}$ of baseline activity as determined by a relatively consistent firing rate and $a<20 \%$ change in action potential amplitude.

The BLA is composed of two subtypes of cells, pyramidal-like principal neurons $(\sim 85 \%)$ and interneurons $(\sim 15 \%$; McDonald, 1985; McDonald and Augustine, 1993; Sah et al., 2003; Rostkowski et al., 2009; Spampanato et al., 2011). Previous articles have demonstrated that principal neurons in the BLA can be identified by typically slow firing rates $(\sim 0.5 \mathrm{~Hz})$ and wider action potential durations. Interneurons can be identified by their shorter action potential duration (Washburn and Moises, 1992; Rainnie et al., 1993; Rosenkranz and Grace, 1999), though this is a tentative classification (Likhtik et al., 2006). To increase the reliability of action potential duration measures, only neurons with a bimodal waveform were included for classification. In the current experiments, there was only a small number of neurons with short action potential duration. Based on the distribution of the action potential full-width duration recorded at the current filter settings, neurons were considered probable interneurons and analyzed separately if they had an action potential width of $<0.9 \mathrm{~ms}$. The firing rate of BLA neurons was determined as the number of action potentials per second (in hertz). The number of spontaneously active cells recorded during the first electrode track was measured to gauge the overall relative neuronal firing activity (West and Grace, 2000; Zhang and Rosenkranz, 2012, 2016).

Glutamate iontophoresis. Upon isolation of a BLA neuron with a stable firing rate, glutamate was applied at the following current intensities: -5 , $-10,-20,-30,-40,-50$, and, when feasible, up to $-80 \mathrm{nA}$. Only neurons that displayed a stable increase of firing during the glutamate iontophoretic step were included in the analysis. The change in firing rate at each current intensity was calculated for each neuron: [Firing Rate $_{\text {glutamate }}-$ Firing Rate $\left._{\text {baseline }}\right]$. These values were averaged for each current intensity.

$G A B A$ iontophoresis. BLA neuronal firing activity is normally low, making it difficult to measure the sensitivity of neuronal firing to GABA. Therefore, glutamate was iontophoretically applied to elicit $5-10 \mathrm{~Hz}$ firing of BLA neurons. GABA was then iontophoretically applied in a dose-dependent manner. GABA was applied at the following current intensities: 5, 10, 20, 30, 40, and $50 \mathrm{nA}$. The percentage change in firing rate at each GABA current intensity was calculated for each neuron: $100+\left[\right.$ Firing Rate $_{\mathrm{GABA}}-$ Firing Rate baseline $] \div$ Firing Rate $_{\text {baseline }}$. The values from this calculation were averaged for each current intensity.

Synaptic events. Postsynaptic events were detected during recording epochs of a minimum of $4 \mathrm{~min}$. The frequency and amplitude of all synaptic events were measured by using a variable-amplitude sliding template with a shape of an average synaptic current (Axograph X). The detection threshold for the events was set at 2.5-3 times the baseline noise $\mathrm{SD}$. The frequency of events (in hertz) and the average amplitude were calculated.

Inhibition/excitation ratio. The balance of inhibition and excitation was calculated for in vivo iontophoresis and in vitro mPSCs. The in vivo inhibition/excitation ratio was calculated by normalizing individual data points for the effect of iontophoretic GABA at each current intensity (as described above) by the average effect of iontophoretic glutamate at the same current intensity: $\left[\right.$ Value $_{\mathrm{GABA}} \div$ Average $_{\mathrm{Glutamate}}$ ], and analyzed as a function current intensity. The in vitro inhibition:excitation ratio was calculated by normalizing individual neuronal data points of mIPSC frequency by the average mEPSC frequency: $\left[\right.$ Value $_{\text {IPSC }} \div$ Average $_{\text {EPSC }}$ ].

Reconstruction of Golgi-stained neurons. Golgi-stained LAT and BA neurons were reconstructed using Neurolucida software (MBF Bioscience) under bright-field illumination $(100 \times$ oil-immersion objective; Eclipse E400 Microscope, Nikon) with CCD camera image acquisition $\left(1600 \times 1200\right.$ pixels, $7.4^{2} \mu \mathrm{m}$ pixel size; Retiga 2000R, QImaging). Rat brain atlases were used to determine LAT and BA borders (Paxinos and Watson, 1998). Only neurons that appeared to be fully impregnated were used. Neurons with breaks $(>5 \mu \mathrm{m})$ in the dendrites were not included. Neurons were selected based on previously described BLA neuron morphology (e.g., large cell bodies with obvious primary dendrites and spines; McDonald, 1982). Neurons that had a morphology consistent with interneurons (bipolar, aspiny dendrites, or small somata with a few aspiny dendrites) were not included in this analysis. Sholl analysis was used to measure spine number in $10 \mu \mathrm{m}$ steps (Sholl, 1953). Measures of spines per branch order were obtained and normalized to the total number of spines [Spines Branch $\div$ Spines $_{\text {Neuron }}$ ] to assess a shift in distribution of spines across the dendritic tree (Padival et al., 2015). Photomicrographs of each individual LAT or BA neuron were collected at similar light settings using a $10 \times, 20 \times$, and $100 \times$ objective. Displayed images were adjusted to grayscale and the sizes of the images were adjusted, and these manipulations were applied equally to all images (Photoshop, Adobe Systems).

\section{Statistical analysis}

Statistical analysis was performed using Prism 5 software (GraphPad Software). Data were compared between males and females (diestrus and proestrus combined) to test whether there are sex differences, or between diestrous and proestrous females to test for cycle stage-dependent differences. Outlier data points were removed if they were $>2.5$ SDs from the mean. This led to the removal of data for one Golgi-stained neuron, two rats in the behavioral tasks, and one neuron recorded in vitro. Data were tested for normality using the D'Agostino and Pearson omnibus normal- 
A
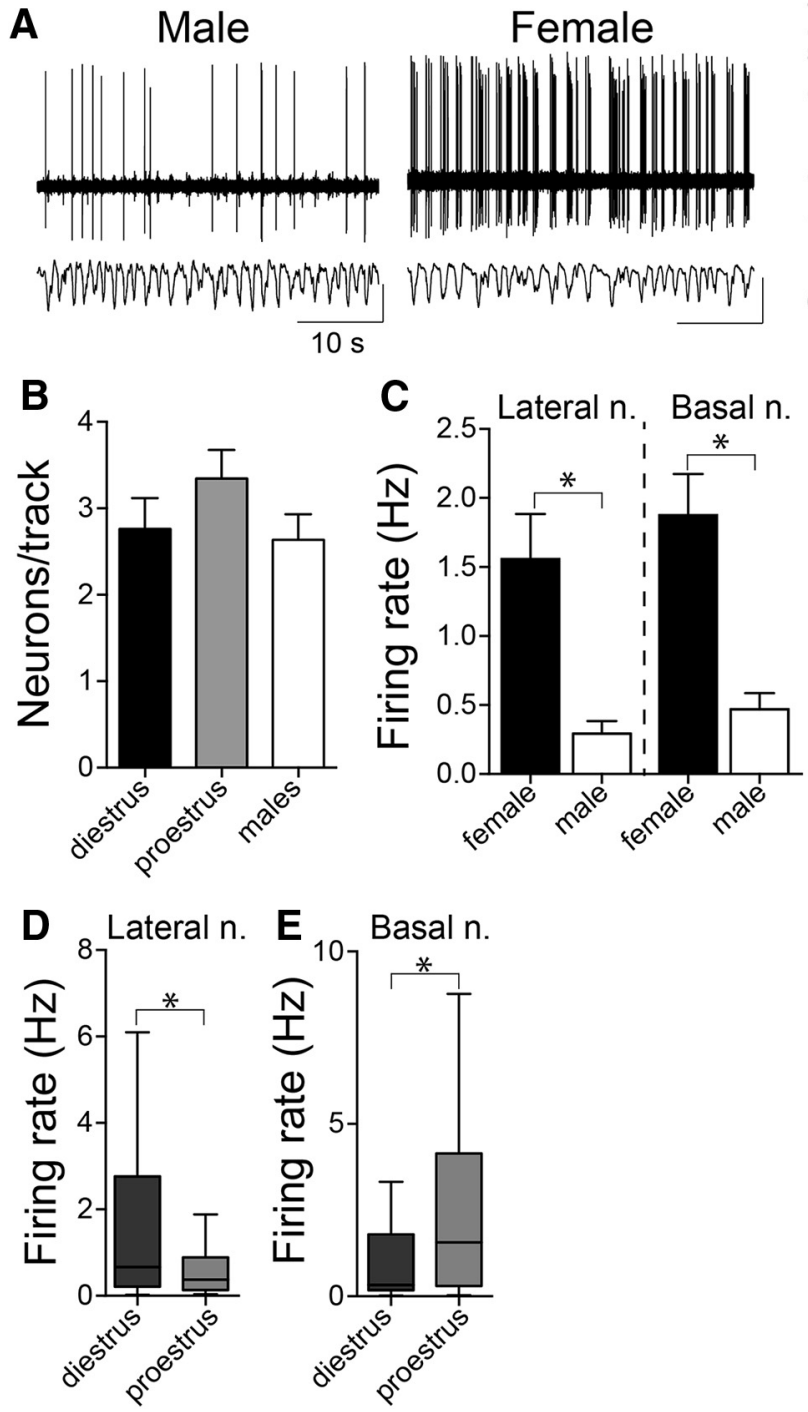

Figure 1. Sex differences in BLA neuron firing rate. $A, B L A$ neurons in females exhibited a higher firing rate compared with males, demonstrated as the number of action potentials per second in these representative recording traces. Depth of anesthesia could contribute to the differences in BLA neuron firing rate and was monitored by cortical local field potential. There was no significant sex difference in the primary component of the cortical oscillation ( $p=0.248$, two-tailed unpaired $t$ test; shown here is box plot with or without Tukey's test). $\boldsymbol{B}$, The number of spontaneously firing BLA neurons per electrode track were similar across female group (diestrus and proestrus) and male group ( $p=0.347$, one-way ANOVA). C, LAT and BA neurons recorded in female rats had significantly higher firing rates than male rats (LAT: $p<0.05$; BA: $p<0.05$; Mann-Whitney $U$ tests). $\boldsymbol{D}$, LAT neurons recorded in diestrous and proestrous females were compared to examine the influence of the estrous cycle on neuronal firing rate. Females in diestrus had a higher LAT neuronal firing rate compared with females in proestrus $(p<0.05$, Mann-Whitney $U$ test; shown here is box plot with or without Tukey's test). $\boldsymbol{E}$, Females in diestrus had a lower BA neuronal firing rate compared with proestrus $\left(p<0.05\right.$, Mann-Whitney $U$ test; shown here is the box plot with or without Tukey's test). ${ }^{*} p<0.05$ Mann-Whitney $U$ test. Calibration $y$-axis: top traces, $20 \mu \mathrm{V}$; bottom traces, $10 \mu \mathrm{V}$.

ity test. If a non-normal distribution was found, appropriate nonparametric analysis was performed. Otherwise, two-tailed $t$ tests to compare two groups, one-way ANOVA to compare more than two groups, or two-way ANOVA to compare along multiple factors were used. A $p \leq$ 0.05 in two-tailed tests was considered statistically significant. All data are displayed as the mean \pm SEM unless specified.

\section{Results}

The estrous cycle was reliably tracked by vaginal lavage, as demonstrated in other studies (Urban et al., 1993; Becker et al., 2005) and was confirmed by endocrine and anatomical measures. Proestrous females had significantly higher estradiol levels compared with diestrous females (diestrus: $114.2 \pm 15.6 \mathrm{pg} / \mathrm{ml}, n=7$; proestrus: $184.3 \pm 20.5 \mathrm{pg} / \mathrm{ml}, n=7 ; p=$ 0.0186, $t=2.720$, two-tailed unpaired $t$ test), confirming the reliability of the estrous cycle phase during charting. Additionally, the uterine horns of proestrous female rats were visibly edematous and hyperemic, which is typical for that cycle stage and the presence of estrogen tone (Becker et al., 2005).

\section{BLA neuron firing activity}

As an initial global overview, activity across the BLA (LAT + BA) was assessed together. BLA neurons in males exhibited a relatively slow firing rate $(0.38 \pm 0.07$ $\mathrm{Hz}, n=40$ neurons from $n=13$ rats), similar to previous findings in anesthetized male rats (Rosenkranz and Grace, 1999; Likhtik et al., 2006; Zhang and Rosenkranz, 2012). There was a significant difference in BLA neuronal firing rate between males and females (Fig. 1A). BLA neurons in both diestrous and proestrous females were more active compared with males (diestrus: $1.82 \pm 0.33 \mathrm{~Hz}, n=80$ neurons from 24 rats; proestrus: $1.55 \pm$ $0.29 \mathrm{~Hz}, n=62$ neurons from 14 rats; males: $0.38 \pm 0.07 \mathrm{~Hz}, n=40$ neurons from $n=13$ rats; $p=0.0004, \mathrm{H}=15.78$, Kruskal-Wallis test; $p<0.05$, Dunn's multiple-comparison test; male compared with diestrus and male compared with proestrus), though there were no differences between the different cycle stages ( $p>0.05$, Dunn's multiple-comparison test). It is possible that differences in the response to anesthesia could contribute to differences in firing. While this itself could indicate important neural sex differences, precautions were taken to ensure a similar depth of anesthesia. Neurons were only included in analysis if the primary cortical oscillation was between 0.5 and $1.0 \mathrm{~Hz}$. The average cortical primary oscillation was not different between males and females (Fig. $1 A$; males, $0.83 \pm 0.04 \mathrm{~Hz}$; females, $0.89 \pm 0.04 \mathrm{~Hz} ; p=0.248, t=$ 1.159 , two-tailed unpaired $t$ test). As a global measurement of overall neuronal firing in the BLA, we examined the number of spontaneously active neurons recorded in the first electrode penetration and compared this between diestrous and proestrous female and male groups. There was no significant difference in the relative number of spontaneously active neurons in the BLA between females and males (Fig. $1 B$; diestrus: $2.76 \pm 0.36$ neurons/track, $n=24$ rats; proestrus: $3.34 \pm 0.33$ neurons/track, $n=14$ rats; males: $2.63 \pm 0.30$ neurons/track, $n=13$ rats; $p=0.347, F_{(2,51)}=1.081$, one-way ANOVA). All remaining analyses was performed separately between LAT and BA.

There was a significant sex difference in the firing rate of LAT neurons, with a higher LAT neuron firing rate in females compared with males (Fig. $1 C$; females: $1.56 \pm 0.33 \mathrm{~Hz}, n=79$ cells in 
25 rats; males: $0.29 \pm 0.09 \mathrm{~Hz}, n=20$ cells in 8 rats; $p=0.002$, Mann-Whitney $U$ test $=441.5)$. To test whether estrous phase influenced LAT neuron activity, neuronal firing was compared between the high estradiol proestrous phase and the low estradiol diestrous phase. The firing of LAT neurons during diestrus was significantly higher than proestrus (Fig. $1 D$; diestrus: $2.21 \pm 0.52 \mathrm{~Hz}, n=47$ cells in 16 rats; proestrus: $0.60 \pm 0.11 \mathrm{~Hz}, n=$ 32 cells in 9 rats; $p=0.021$, Mann-Whitney $U$ test $=521.5$ ). Previous studies suggest that BLA neurons recorded in anesthetized male rats exhibit little spontaneous bursting activity (Rosenkranz and Grace, 2001; Likhtik et al., 2006; Zhang and Rosenkranz, 2012). To test whether this is also true in females, we calculated the variability in the interspike interval for each neuron [coefficient of variation $(\mathrm{CV})]$. There was no difference in the CV of LAT neuron firing across female and male groups (diestrus: $1.35 \pm$ 0.081 ; proestrus: $1.49 \pm 0.131$; males: $1.33 \pm 0.096 ; p=0.515, \mathrm{H}(2)=1.327$, Kruskal-Wallis test). To verify that we are likely recording a similar population of neurons across rats, the action potential width was compared, and found to be statistically similar across groups $(p=0.876$, $\mathrm{H}(2)=0.265$, Kruskal-Wallis test).

There was also a significant sex difference in the firing rate of BA neurons. The BA neuronal firing rate was significantly higher in females compared with males (Fig. 1C; females: $1.88 \pm 0.30 \mathrm{~Hz}, n=63$ cells in 33 rats; males: $0.47 \pm 0.12 \mathrm{~Hz}, n=$ 20 cells in 9 rats; $p=0.006$, Mann-Whitney $U$ test $=375.5)$. There was also a significant difference across estrous cycle, however, in the opposite direction as LAT. The firing of BA neurons during diestrus was significantly lower than during proestrus (Fig. 1E; diestrus: $1.26 \pm 0.29 \mathrm{~Hz}, n=33$ cells in 11 rats; proestrus: $2.56 \pm 0.52 \mathrm{~Hz}$, $n=30$ cells in 10 rats; $p=0.0255$, Mann-Whitney $U$ test $=333$ ). There was no difference in the CV of BA neuron firing across female and male groups (diestrus: $1.47 \pm 0.16$; proestrus: $1.60 \pm$ 0.15 ; males: $1.45 \pm 0.08 ; p=0.742, \mathrm{H}(2)=0.597$, KruskalWallis test) consistent with similar firing patterns. In addition, there was no significant difference in the action potential widths (Kruskal-Wallis test, $p=0.998, \mathrm{H}(2)=0.005$ ), which is consistent with recordings of a similar population of neurons across groups. These results indicate sex differences in LAT and BA neuronal firing and the opposite direction of changes in neuronal firing between LAT and BA across the estrous cycle.

\section{Glutamatergic drive of BLA neurons}

Spontaneous firing reflects only one aspect of neural activity. Glutamatergic inputs can potently activate BLA neurons. Therefore, sex differences in glutamatergic drive may lead to sex differences in BLA function and may contribute to the observed sex differences in firing rate.
B Lateral $\mathrm{n}$.

C

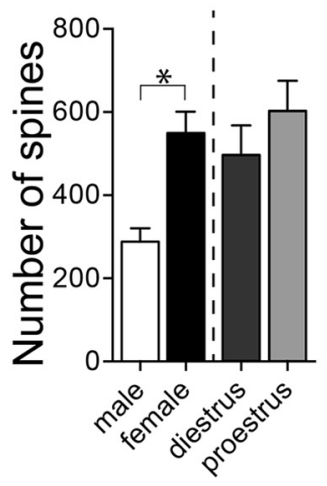

E

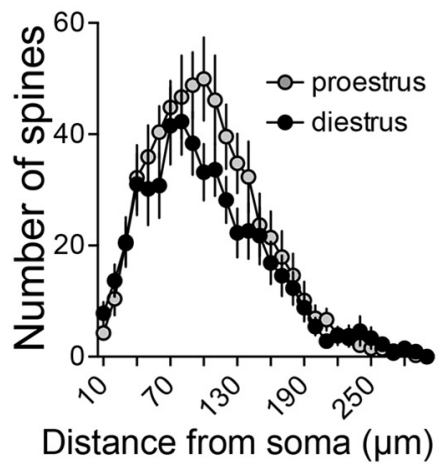

$\mathbf{F}$

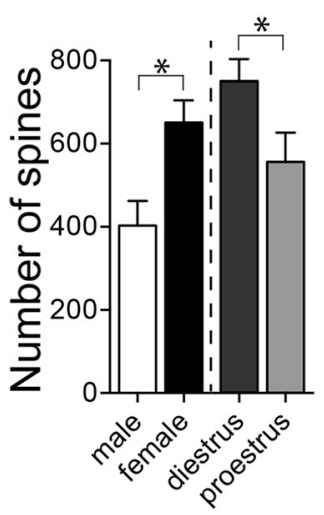

Figure 2. Sex differences in LAT and BA neuron morphology. $\boldsymbol{A}$, Representative pictures of Golgi-Cox-stained LAT neurons in a female (top) and a male (bottom) rat. Scale bars: $20 \mu \mathrm{m}$; inset, $5 \mu \mathrm{m}$. $\boldsymbol{B}$, There were significantly more spines in LAT neurons in

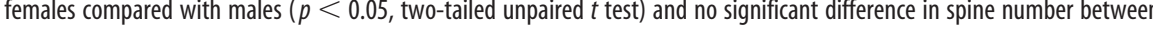
diestrous and proestrous females ( $p=0.282$, two-tailed unpaired $t$ test). $\boldsymbol{C}$, Across the dendritic tree there were no differences in ( 0.294 , two-way RM-ANOVA) between diestrous and proestrous females. $\boldsymbol{D}$, Representative pictures of Golgineurons was higher in females compared with males ( $p<0.05$ two-tailed unpaired $t$ test) and was dependent on the estrous cycle where BA neurons in diestrous females had more spines compared with BA neurons in proestrous females (right; $p=0.050$, two-tailed unpaired $t$ test). $\boldsymbol{F}, A$ greater number of spines was observed across the dendritic tree in $B A$ neurons from diestrous females ( $p<0.05$, two-way RM-ANOVA). ${ }^{*} p<0.05$ two-tailed unpaired $t$ test; ${ }^{* *} p<0.05$ two-way RM-ANOVA.

\section{Excitatory inputs to BLA}

Increased neuronal activity observed in females may occur due to a greater number of excitatory inputs. Most glutamatergic inputs synapse onto spines of BLA neurons (Farb et al., 1992; BrinleyReed et al., 1995; Muller et al., 2006; Radley et al., 2007; Rademacher et al., 2010). A change in spine number can therefore reflect a change in excitatory input. To examine whether there are differences in spine number between sex or estrous phase, Golgiimpregnated BLA neurons in diestrous and proestrous females and males were reconstructed for morphological analysis (Fig. $2 A, D)$. BLA neurons were separated based on their location in the LAT or BA nuclei.

While LAT neurons had a similar overall dendritic length in males and females (males: $2752 \pm 242.7 \mu \mathrm{m}, n=16$ cells from 5 rats; females: $2992 \pm 242.0 \mu \mathrm{m}, n=32$ cells from 10 rats; $p=$ $0.534, t=0.626$, two-tailed unpaired $t$ test), the same LAT neurons in females had significantly more spines than males (Fig. 2B; males: $288.1 \pm 28.3$ spines; females: $549.8 \pm 48.6$ spines; $p=$ $0.0007, t=3.638$, two-tailed unpaired $t$ test). However, there was no significant difference in spine number across the estrous cycle 
A Lateral $\mathrm{n}$.

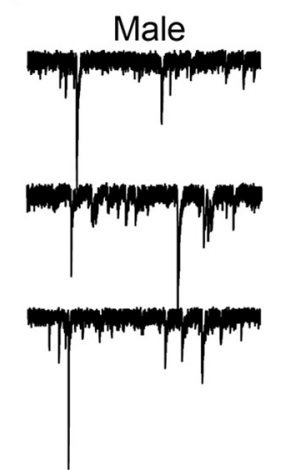

C Basal $n$.

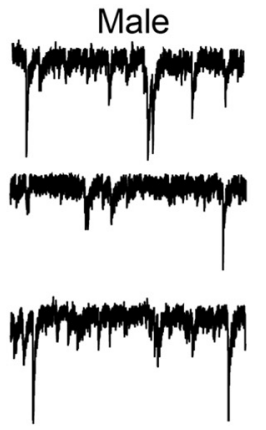

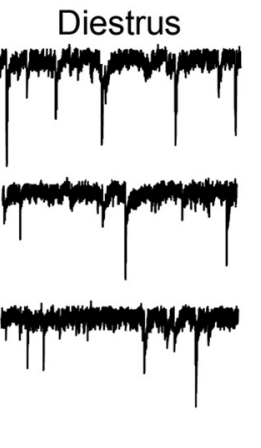
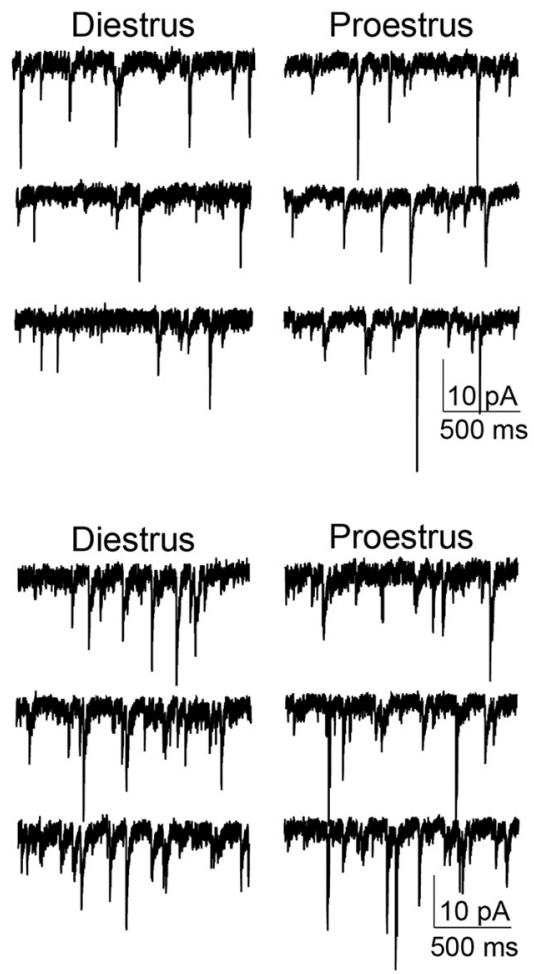

B
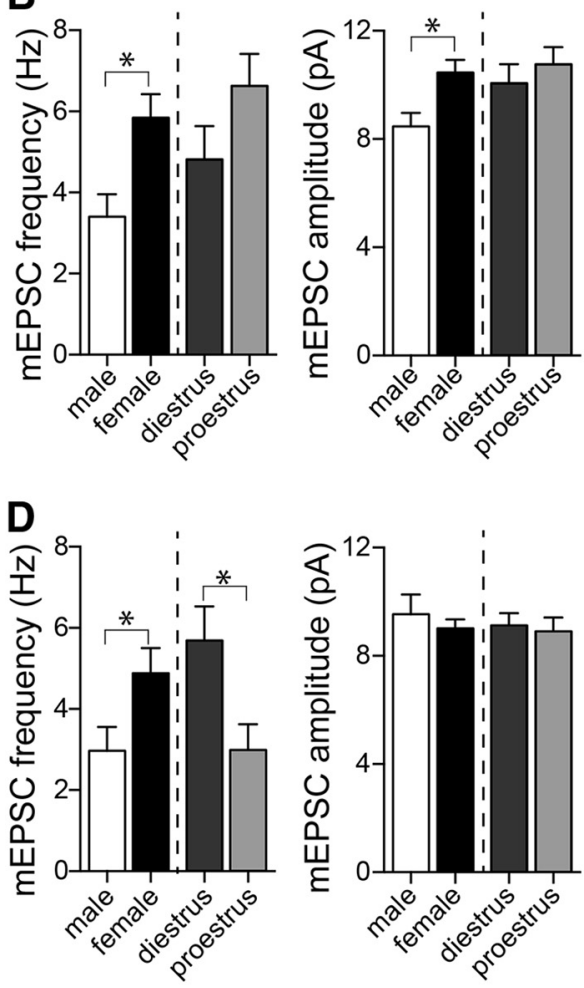

Figure 3. Greater excitatory synaptic input in LAT and BA neurons in females. $m E P S C S$ were measured from LAT principal neurons in vitro in female and male animals to determine whether the observed anatomical differences had a functional correlate. $\boldsymbol{A}$, Displayed here are representative traces of $\mathrm{mEPSC}$ recordings in male and female groups. $\boldsymbol{B}$, Females had a significantly higher frequency of mEPSCs in LAT neurons (left: $p<0.05$, two-tailed unpaired $t$ test) and greater amplitude of mEPSCs compared with males (right: $p<0.05$, two-tailed unpaired $t$ test). $\mathrm{mEPSC}$ frequency (left: $p=0.124$, two-tailed unpaired $t$ test) and amplitude (right: $p=0.757$, two-tailed unpaired $t$ test) did not differ across the estrous cycle. $C$, Representative traces of mEPSC recordings in BA neurons in male and female groups. $\boldsymbol{D}$. The frequency of mEPSCs in BA neurons was greater in females compared with males (left: $p<0.05$, two-tailed unpaired $t$ test); however, there was no difference in mEPSC amplitude between sexes (right: $p=0.463$, two-tailed unpaired $t$ test). The frequency of mEPSCs was significantly higher in diestrous females compared with proestrous females (left: $p<0.05$, two-tailed unpaired $t$ test); however, mEPSC amplitudes were similar between the cycle stages (right: $p=0.757$, two-tailed unpaired $t$ test). ${ }^{*} p<0.05$, two-tailed unpaired $t$ test.

when measured as the total number of spines (Fig. 2B; diestrus: $496.8 \pm 66.96$; proestrus: $602.9 \pm 70.1 ; n=16$ cells from 5 rats/group; $p=0.282, t=1.095$, two-tailed unpaired $t$ test) or when measured by Sholl analysis across the dendritic tree [Fig. 2C; main effect of estrous phase: $p=0.294, F_{(1,30)}=1.141$; estrous phase $\times$ dendritic distance interaction. $p=0.249, F_{(29,870)}=1.168$; two-way repeated-measures (RM) ANOVA]. In addition, there was no significant shift in the distribution of spines across the multiple branch orders of neurons over the estrous cycle (main effect of estrous phase: $p=0.158, F_{(1,30)}=2.094$; estrous phase $\times$ branch order interaction: $p=0.919, F_{(13,390)}=0.510$; two-way RM-ANOVA).

BA neurons displayed a similar pattern of sex differences, with a significantly greater number of spines in BA neurons from female rats compared with male rats (Fig. 2E; males: $403.3 \pm 54.9$ spines, $n=16$ cells from 4 rats; females: $650.7 \pm 50.6$ spines, $n=$ 33 cells from 10 rats; $p=0.0042, t=3.010$, two-tailed unpaired $t$ test), without a significant difference in total dendritic length of the same neurons (males: $3387 \pm 263.9 \mu \mathrm{m}, n=16$ cells from 4 rats; females: $4150 \pm 525.9 \mu \mathrm{m}, n=33$ cells from 10 rats; $p=$ $0.333, t=0.978$, two-tailed unpaired $t$ test). Different than LAT, however, there was a significant difference in spine number across the estrous cycle, with more spines on BA neurons during diestrus compared with proestrus (Fig. 2E; diestrus: $753.8 \pm 71.1$; proestrus: $556.5 \pm 65.7 ; n=16-17$ cells from 5 rats/group; $p=$ $0.050, t=2.02$, two-tailed unpaired $t$ test). This difference was spread over a range of dendritic distances (Fig. 2F; main effect of estrous phase: $p=0.0432, F_{(1,31)}=4.440$; estrous phase $\times$ branch order interaction: $p=0.978, F_{(29,899)}=0.540$, two-way RMANOVA) but was not associated with a significant shift in the distribution of spines across dendritic branches (main effect of estrous phase: $p=0.158, F_{(1,20)}=2.094$; estrous phase $\times$ branch order interaction: $p=0.919, F_{(13,390)}=0.510$, two-way RM-ANOVA).

\section{Excitatory synaptic input}

To test whether the anatomical indication of increased excitatory inputs has a functional correlate, we examined glutamatergic synaptic quantal frequency and quantal amplitude by measuring mEPSCs in principal neurons in brain slices from male and female rats.

In LAT neurons, the frequency of mEPSC events was greater in females compared with males (Fig. $3 A, B$; females: $5.84 \pm 0.58 \mathrm{~Hz}$, $n=39$ cells from 8 rats; males: $3.40 \pm 0.56 \mathrm{~Hz}, n=17$ cells from 5 rats; $p=0.0138, t=2.55$, two-tailed unpaired $t$ test). There was no significant difference across estrous cycles in MEPSC frequency (Fig. $3 B$; proestrus: $6.63 \pm 0.79 \mathrm{~Hz}, n=22$ cells from 4 rats; diestrus: $4.82 \pm 0.82 \mathrm{~Hz}, n=17$ cells from 5 rats; $p=0.1235$, $t=1.576$, two-tailed unpaired $t$ test). The amplitude of mEPSCs was greater in LAT of females $(10.46 \pm 0.47 \mathrm{pA})$ compared with males ( $8.46 \pm 0.51 \mathrm{pA} ; p=0.014, t=2.54$, two-tailed unpaired $t$ test), but there was no significant difference in mEPSC amplitude across the estrous cycle (proestrus: $10.77 \pm 0.64 \mathrm{pA}$; diestrus: $10.06 \pm 0.70 ; p=0.466, t=0.7367$, two-tailed unpaired $t$ test $)$. 

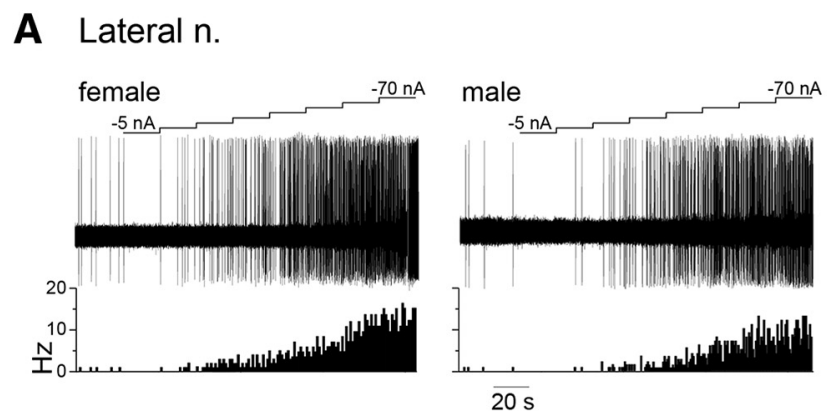

\section{Basal $n$.}

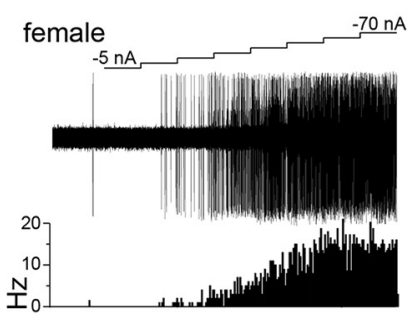

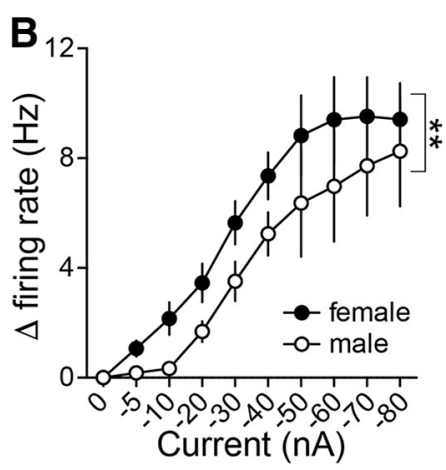

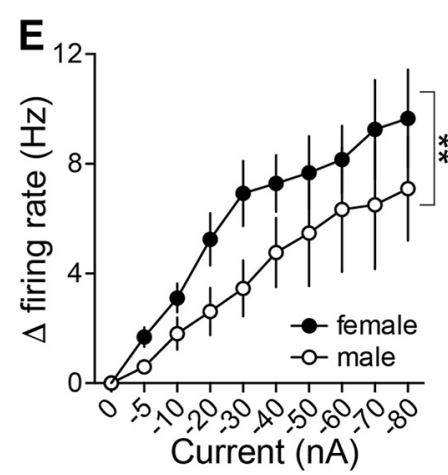

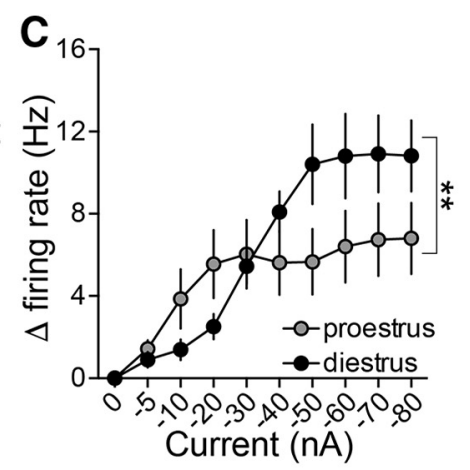

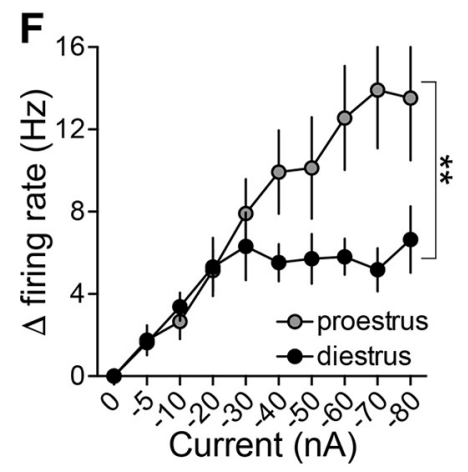

Figure 4. Glutamate iontophoresis drives LAT and BA neuronal firing rate more effectively in females than males. $A$, Representative traces of iontophoretic current applied to eject glutamate (top), the neuronal response to glutamate (middle), and a time histogram of the firing rate ( $\mathrm{Hz}$ ) of the neuron across time (bottom) in LAT neurons recorded in a female (left) and male (right) rat. $B$, Glutamate drove LAT neuron firing more effectively in females compared with males $(p<0.05$, two-way ANOVA). C, The effectiveness of glutamate to drive LAT neurons was dependent on the estrous cycle stage, where glutamate was more effective at lower current applications in proestrous females and higher current applications were more effective in diestrous females $(p<0.05$, two-way ANOVA). $\boldsymbol{D}$, Representative traces of iontophoretic current applied to eject glutamate (top), the neuronal response to glutamate (middle), and a time histogram of the firing rate $(\mathrm{Hz})$ of the neuron across time (bottom) in BA neurons recorded in a female (left) and male (right) rat. $\boldsymbol{E}$, Glutamate drove BA neuron firing more effectively in females compared with males $(p<0.05$, two-way ANOVA). $\boldsymbol{F}, \mathrm{BA}$ neurons in proestrous females were more responsive to glutamate iontophoresis compared with diestrous females $(p<0.05$, two-way ANOVA). ${ }^{* *} p<0.05$, two-way ANOVA.

In BA neurons, the frequency of mEPSC events was greater in females (Fig. $3 C, D ; 4.51 \pm 0.60 \mathrm{~Hz}, n=29$ cells from 8 rats) compared with males $(2.97 \pm 0.59 \mathrm{~Hz}, n=15$ cells from 5 rats; $p=0.049, t=2.028$, two-tailed unpaired $t$ test). The frequency of mEPSCs also varied across the estrous cycle, with a higher mEPSC frequency in BA neurons in diestrous females compared with proestrous females (Fig. 3D; diestrus: $5.69 \pm 0.85 \mathrm{~Hz}, n=14$ cells from 4 rats; proestrus: $2.99 \pm 0.64 \mathrm{~Hz}, n=15$ cells from 4 rats; $p=0.016, t=2.574$, two-tailed unpaired $t$ test). There was no difference between males and females overall in BA mEPSC amplitude (females: $9.01 \pm 0.34 \mathrm{pA}$; males: $9.53 \pm 0.74 \mathrm{pA} ; p=$ $0.463, t=7.42$, two-tailed unpaired $t$ test) or across the estrous cycle (diestrus: $9.121 \pm 0.456 \mathrm{pA}$; proestrus: $8.91 \pm 0.510 \mathrm{pA}, p=$ $0.757, t=0.312$, two-tailed unpaired $t$ test). These data complement the anatomical evidence for sex differences in excitatory input across the BA and LAT, and estrous phase differences in the BA.

In vivo sensitivity to glutamate

Differences in synaptic inputs measured above demonstrate the potential for increased glutamatergic drive of BLA neurons in females. To directly test the link between glutamatergic drive and in vivo firing, the firing response of BLA neurons to iontophoretic glutamate was measured. Glutamate was iontophoretically applied in increasing currents, leading to increased firing of neurons (Fig. $4 A, D$ ).

Glutamate iontophoresis drove the firing of LAT neurons in female rats more than male rats (Fig. $4 B$; main effect of sex: $p=$ $0.0004, F_{(1,376)}=12.78$; males: $n=19$ cells in 7 rats; females: $n=$
29 cells in 13 rats, two-way ANOVA). In female rats, the effect of glutamate on LAT neurons differed across the estrous cycle (Fig. $4 C$; main effect of estrous phase: $p=0.0316, F_{(1,234)}=4.678$; diestrus: $n=16$ cells in 7 rats; proestrus: $n=13$ cells in 6 rats, two-way ANOVA), with greater response to low glutamate current applications in proestrus and a greater response to high glutamate current applications in diestrus (Fig. 4C; estrous phase $\times$ current interaction: $p=0.0133, F_{(9,234)}=2.387$, two-way ANOVA).

When recording BA neurons, a similar sex difference was observed. BA neurons in female rats were significantly more responsive to glutamate iontophoresis than male rats (Fig. $4 D, E$; main effect of sex: $p=0.0015, F_{(1,327)}=10.23$; males: $n=10$ cells in 7 rats; females: $n=32$ cells in 13 rats, two-way ANOVA). The effectiveness of glutamate to drive BA neuron firing differed across the cycle, with a greater impact during proestrus than diestrus (Fig. 4F; main effect of estrous phase: $p<0.0001, F_{(1,248)}=$ 25.99; diestrus: $n=18$ cells in 7 rats; proestrus: $n=14$ cells in 6 rats, two-way ANOVA). This demonstrates greater sensitivity of BLA neurons to glutamate in females to accompany greater glutamatergic synaptic input and that this sensitivity changes over the estrous cycle.

These data suggest a parallel greater number of synaptic spines and synaptic sites that may augment responses to iontophoretic glutamate, and increased the firing of LAT and BA neurons in females compared with males. However, this series of differences does not explain shifts in LAT and BA activity across the estrous cycle. The shift of LAT/BA neuron firing and glutamate sensitiv- 
A

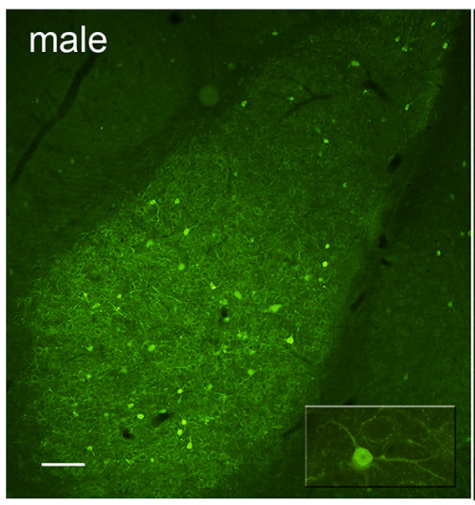

B Lateral $\mathrm{n}$.

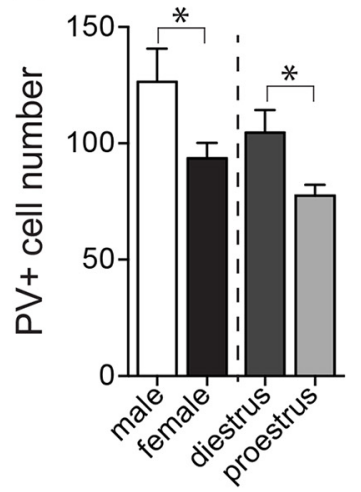

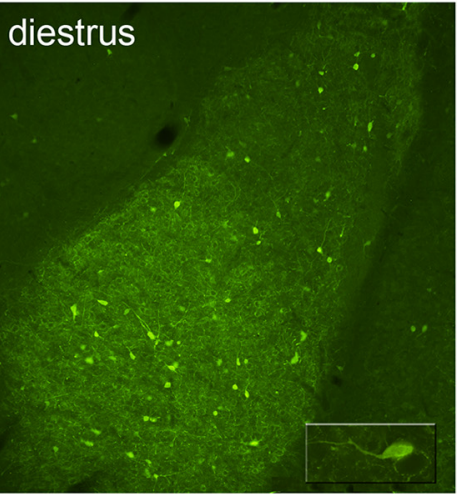

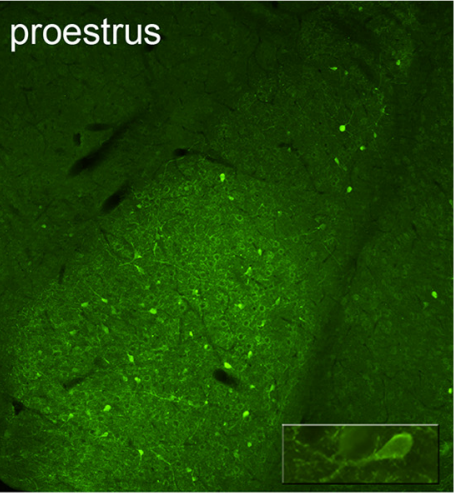

Basal n.
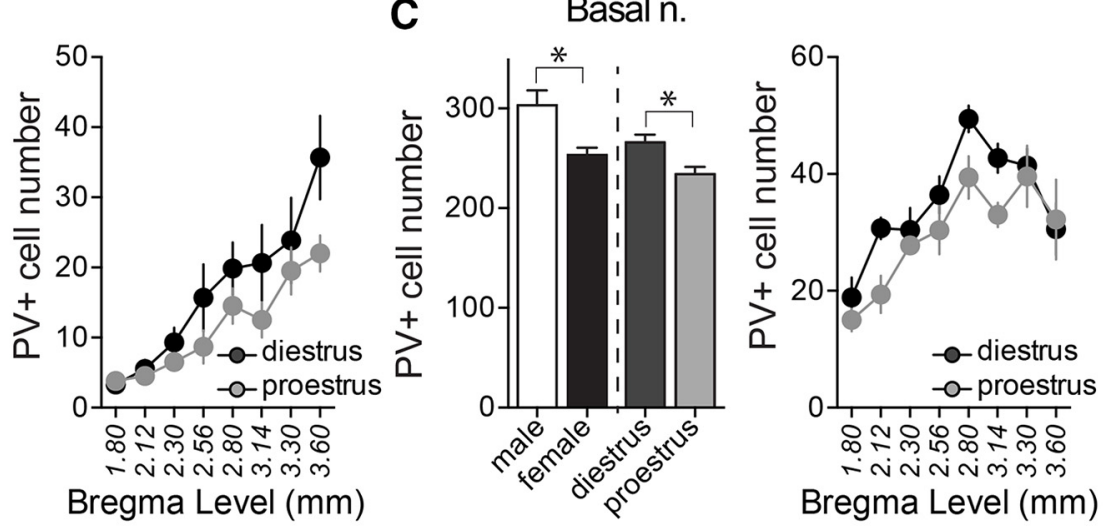

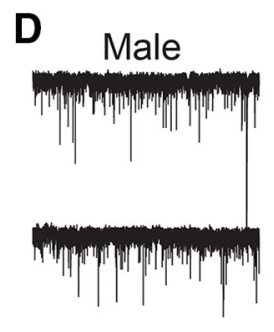

PrTy
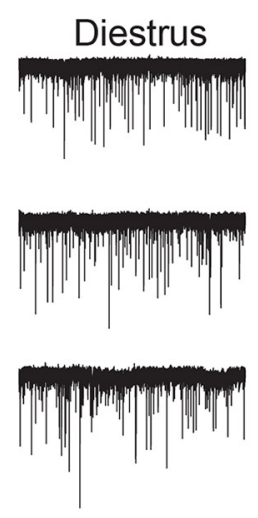
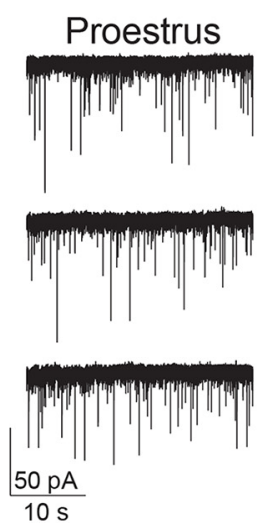
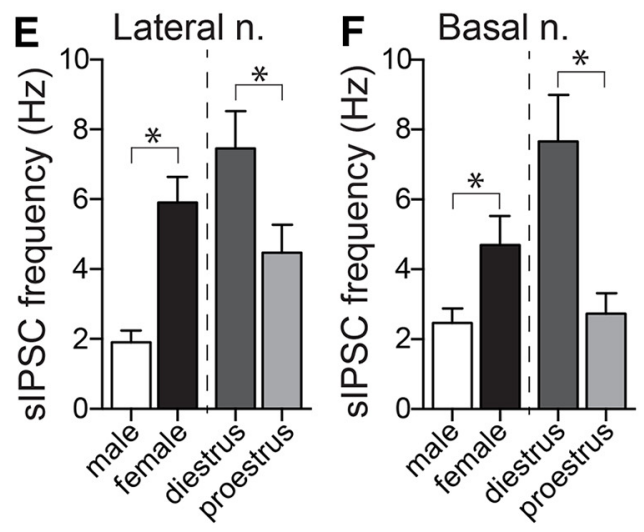

Figure 5. PV-immunopositive cell numbers are decreased in the BLA of female rats in proestrus. $A$, Representative images of PV staining of LAT and BA nuclei, in diestrous, proestrous, and male groups ( $-2.56 \mathrm{~mm}$ from bregma). Inset depicts higher-magnification image of single cells. $\boldsymbol{B}$, The number of PV ${ }^{+}$neurons in the LAT nucleus was significantly higher in male compared with female rats $\left(p=0.0321\right.$, two-tailed unpaired $t$ test). Females in proestrus had lower numbers of $\mathrm{PV}^{+}$neurons in the LAT nucleus compared with females in diestrus $(p=0.0288$, two-tailed unpaired $t$ test), and this was observed across rostral-caudal regions. C, Males had a higher number of $\mathrm{PV}^{+}$neurons in the BA nucleus compared with females ( $p=0.0045$, two-tailed unpaired $t$ test), and proestrous females had lower numbers of $\mathrm{PV}^{+}$neurons than diestrous females $(p=0.0210$, two-tailed unpaired $t$ test). $\boldsymbol{D}$, sIPSCs were measured in LAT neurons and BA neurons to examine GABAergic synaptic input. Shown here are examples of $s$ IPSC recorded from BA slices obtained from a male, a diestrus female, and a proestrus female rat. $\boldsymbol{E}$, The sIPSC frequency in LAT neurons was higher in females compared with males ( $p=0.0015$, two-tailed unpaired $t$ test). Across the estrous cycle, there was a lower frequency of sIPSCs in LAT neurons during proestrus ( $p=0.0291$, two-tailed unpaired $t$ test). $F$, In a similar manner, the sIPSC frequency in BA neurons was higher in females compared with males ( $p=0.0254$, two-tailed unpaired $t$ test). Across the estrous cycle, there was a lower frequency of sIPSCS in BA neurons during proestrus ( $p=0.0002$, two-tailed unpaired $t$ test). ${ }^{*} p<0.05$, two-tailed unpaired $t$ test. Scale bar, $100 \mu \mathrm{m}$.

ity across the estrous cycle did not match the shifts in spine number or $\mathrm{mEPSC}$ frequency. The mismatched shifts in the postsynaptic response to glutamate iontophoresis and spine number across the estrous cycle could still be reconciled if there was a change in the receptor sensitivity to glutamate. However, the amplitude of mEPSCs was similar across the cycle, which is inconsistent with a change in the receptor sensitivity to glutamate. This points to other factors that may be influencing the link between glutamatergic input number, response to glutamate and neuronal firing.

\section{GABAergic inhibition of BLA neurons}

GABAergic inhibition is a key factor that regulates neuronal firing. Differences in inhibitory synaptic input may contribute to the sex differences observed in BLA neuronal activity.

\section{$P V$-immunopositive interneurons in the BLA}

$\mathrm{PV}$-immunopositive $\left(\mathrm{PV}^{+}\right)$interneurons provide the main source of GABAergic inhibition in the BLA. The number of $\mathrm{PV}^{+}$ cells was quantified across the BLA (Fig. 5) and demonstrated a rostral-caudal distribution whereby more cells were noted in the 
A Lateral $\mathrm{n}$.
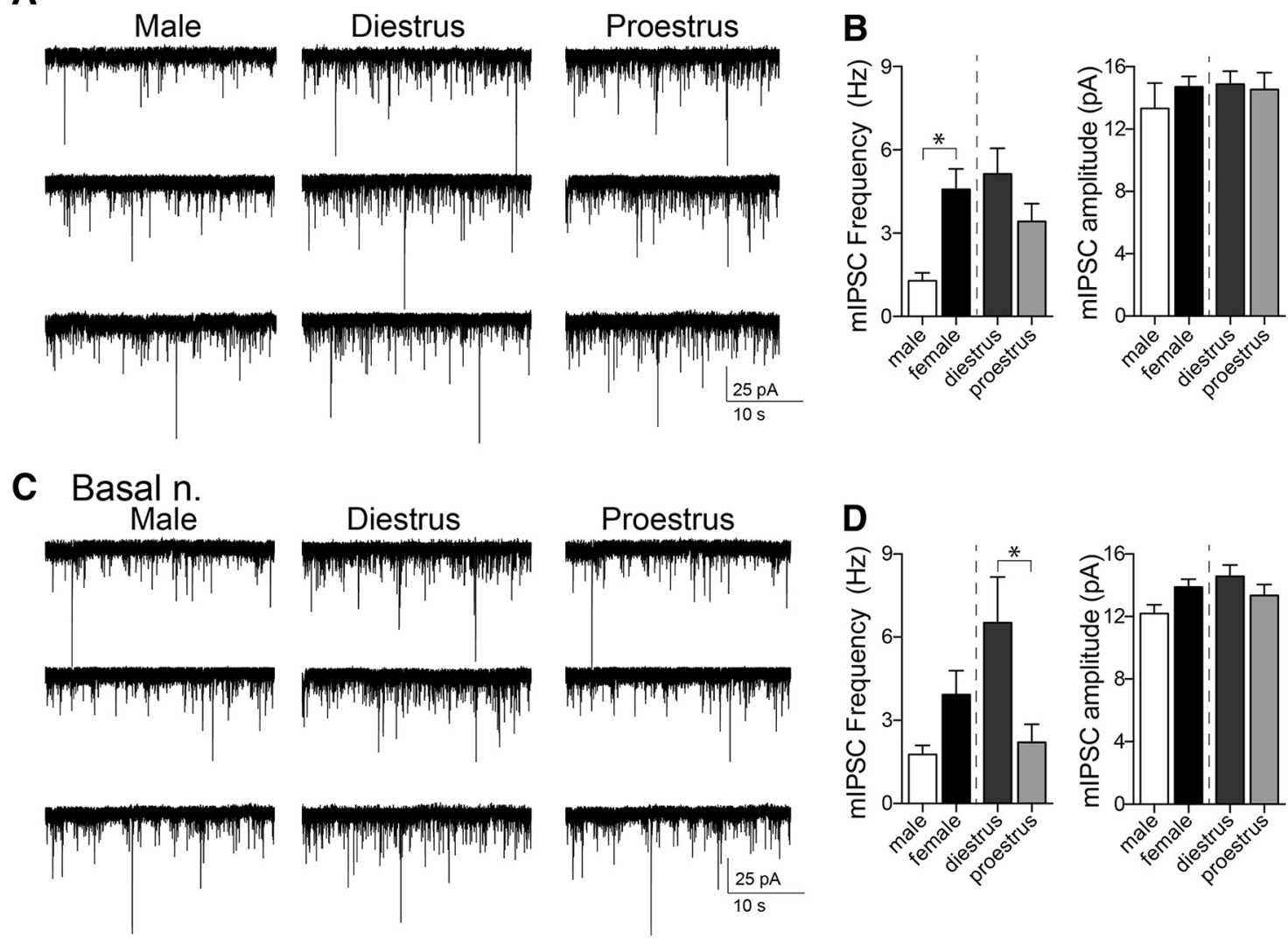

Figure 6. mIPSC frequency in BA neurons is higher in diestrous females. To examine the effect of sex/estrous cycle on GABA release probability and number of synapses, mIPSCs were measured in female and male groups. $A$, Representative traces of $\mathrm{mIPSC}$ s recorded from LAT neurons in male and female groups. $\boldsymbol{B}$, Females had greater mIPSC frequencies in LAT neurons compared with males (left; $p<0.05$, two-tailed unpaired $t$ test); however, the frequency of mIPSCs did not differ between diestrous and proestrous groups (left; $p=0.135$, two-tailed unpaired $t$ test). There were no differences in mIPSC amplitudes between males and females (right; $p=0.3547$, two-tailed unpaired $t$ test), or diestrous and proestrous females (right; $p=0.8010$, two-tailed unpaired $t$ test). C, Representative traces of mIPSCs recorded from BA neurons in male and female groups. $\boldsymbol{D}$, In BA neurons, males and females had similar mIPSC frequencies (left; $p=0.129$, two-tailed unpaired $t$ test) and no differences in mIPSC amplitudes (right; $p=0.0576$, two-tailed unpaired $t$ test). Diestrous females had greater mIPSC frequencies compared with proestrous females (left; $p<0.05$, two-tailed unpaired $t$ test), with no differences in mIPSC amplitudes observed (right; $p=0.2401$, two-tailed unpaired $t$ test). ${ }^{*} p<0.05$, two-tailed unpaired $t$ test.

caudal aspects of the complex. The total number of $\mathrm{PV}^{+}$cells was significantly lower in females compared with males in both the LAT (Fig. $5 B ; p=0.0321, t=2.347$, df $=16$; males: $n=7$ rats; females: $n=11$ rats, two-tailed unpaired $t$ test) and BA (Fig. $5 C$; $p=0.0045, t=3.338, \mathrm{df}=15$; males: $n=7$ rats; females: $n=10$ rats; two-tailed unpaired $t$ test). When accounting for estrous cyclicity, the number of $\mathrm{PV}^{+}$cells was lower in proestrous compared with diestrous females in the LAT (Fig. $5 B$; LAT; $p=$ $0.0288, t=2.60$, $\mathrm{df}=9$; diestrus: $n=6$; proestrus: $n=5$; twotailed unpaired $t$ test) and the BA (Fig. $5 C ; p=0.0210, t=2.865$, df $=8$; diestrus: $n=6$ rats; proestrus: $n=4$ rats, two-tailed unpaired $t$ test). Though not readily quantifiable, there was an observed decrease in the incidence of $\mathrm{PV}^{+}$pericellular basket staining in the BA during proestrus. While there are significant changes in the number of $\mathrm{PV}^{+}$cells (interneurons) across the cycle, it is not likely that this represents the generation of new neurons per se. As noted in other studies, the expression of PV within various brain regions is activity dependent (Carder et al., 1996; Patz et al., 2004), and, therefore, the alterations observed in the number of $\mathrm{PV}^{+}$neurons may reflect the activity of the PV class of interneurons. Measurement of spontaneous IPSCs can reflect firing of interneurons; therefore, to test for differences in the activity of interneurons, sIPSCs were measured.

\section{Inhibitory synaptic input}

To test whether there are functional differences in GABAergic inhibition, we measured the frequency and amplitude of sIPSC and mIPSC in brains slices from diestrous and proestrous females and males.

The sIPSC frequency in LAT neurons was higher in females compared with males (Fig. $5 E$; males: $1.90 \pm 0.31 \mathrm{~Hz}, n=10$ cells from 7 rats; females: $5.91 \pm 0.70 \mathrm{~Hz}, n=27$ cells from 10 rats; $p=$ $0.0015, t=3.454$, two-tailed unpaired $t$ test). Across the estrous cycle, there was a lower frequency of sIPSCs in LAT neurons during proestrus (Fig. $5 E$; diestrus: $7.45 \pm 1.04, n=13$ cells from 5 rats; proestrus: $4.47 \pm 0.79, n=14$ cells from 5 rats; $p=0.0291$, $t=2.315$, two-tailed unpaired $t$ test). There was no difference in sIPSC amplitude in LAT neurons between males and females (males: $15.67 \pm 1.51 \mathrm{pA}$; female: $18.44 \pm 0.83 \mathrm{pA} ; p=0.0977, t=$ 1.705 , two-tailed unpaired $t$ test) and across the estrous cycle (diestrus: $19.08 \pm 1.00 \mathrm{pA}$; proestrus: $17.85 \pm 1.33 \mathrm{pA} ; p=0.470$, $t=0.7340$, two-tailed unpaired $t$ test).

In a similar manner, the sIPSC frequency in BA neurons was higher in females compared with males (Fig. 5F; males: $2.28 \pm$ $0.34 \mathrm{~Hz}, n=12$ cells from 8 rats; females: $4.97 \pm 0.75, n=27$ cells from 11 rats; $p=0.0254, t=2.330$, two-tailed unpaired $t$ test). Across the estrous cycle, there was a lower frequency of sIPSCs in BA neurons during proestrus (Fig. $5 F$; diestrus: $7.78 \pm 1.09 \mathrm{~Hz}$, 
A Lateral $\mathrm{n}$.

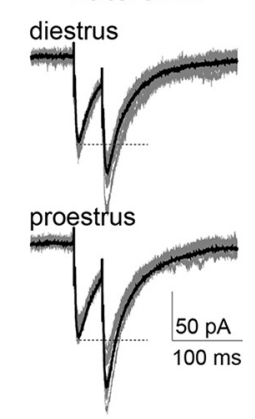

B Basal $n$.

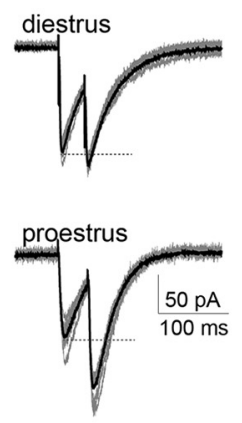

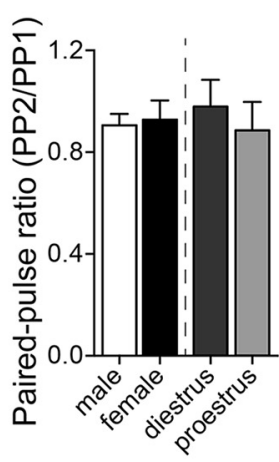

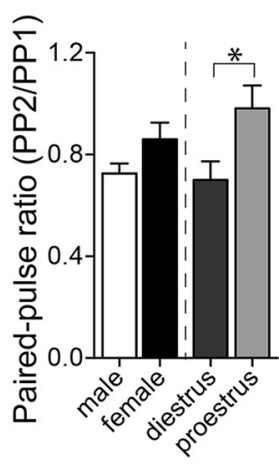

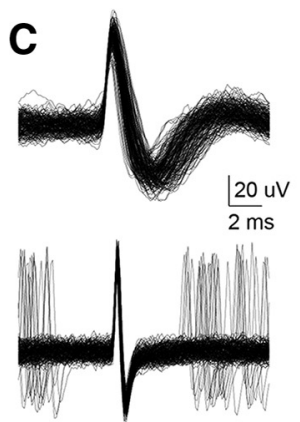

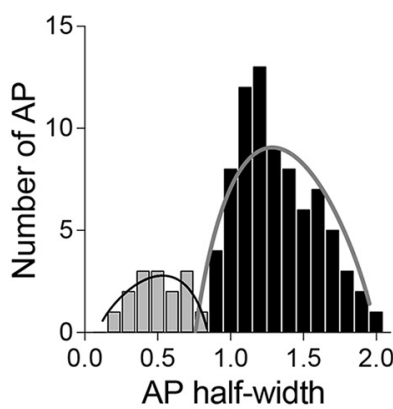

D Lateral $n$.

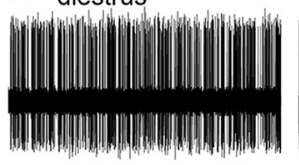

E Basal $n$.

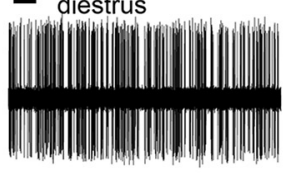

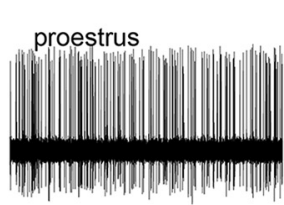
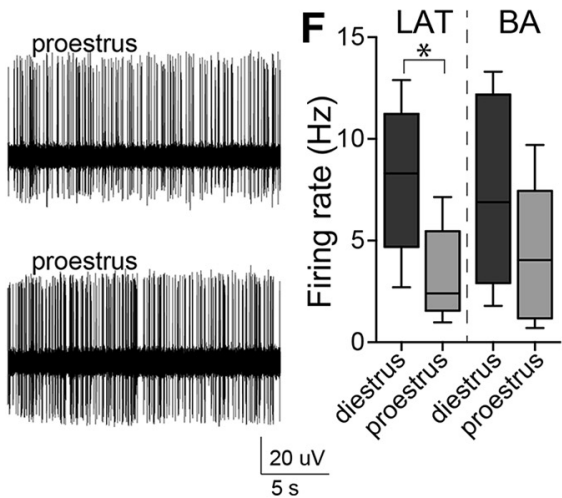

Figure 7. Paired-pulse stimulation and interneuron firing activity indicate different sources for estrous cyclicity in LAT and BA. Paired-pulse stimulation of GABAergic input was measured. $A$, Representative examples of paired-pulse responses recorded from a LAT neuron during diestrus or proestrus (gray: 10 consecutive responses; black: average). There was no difference in the paired-pulse ratio of GABAergic input across the estrous cycle in LAT neurons (right; $p=0.5550$, two-tailed unpaired $t$ test). $B$, Representative examples of paired-pulse responses recorded from a $B A$ neuron during diestrus or proestrus (gray: 10 consecutive responses; black: average). There was a significant shift in the paired-pulse ratio of $G A B A e r g i c$ input across the estrous cycle in BA neurons (right; $p<0.05$, two-tailed unpaired $t$ test). C, Presumptive interneurons displayed a short action potential half-width compared with principal neurons (left). Based on the distribution of half-widths, a cutoff of $<0.9$ ms was used to identify presumptive interneurons (right). $\boldsymbol{D}$, Representative example of a presumptive LAT interneuron firing recorded in a diestrous or proestrous female. $\boldsymbol{E}$, Representative example of a presumptive BA interneuron firing recorded in a diestrous or proestrous female. $\boldsymbol{F}$, The average firing rate of presumptive $L A T$ interneurons was significantly higher in diestrous compared with proestrous females ( $p<0.05$, two-tailed unpaired $t$ test). In contrast, the average firing rate of presumptive BA interneurons was not significantly different across the estrous cycle ( $p=0.2547$, two-tailed unpaired $t$ test; shown here is the box plot with or without Tukey's test). ${ }^{*} p<0.05$, two-tailed unpaired $t$ test.

$n=12$ cells from 6 rats; proestrus: $2.73 \pm 0.57 \mathrm{~Hz}, n=15$ cells from 5 rats; $p=0.0002, t=4.361$, two-tailed unpaired $t$ test). sIPSC amplitude was not significantly different between males and females (males: $15.32 \pm 0.55 \mathrm{pA}$; females: $16.98 \pm 0.70 \mathrm{pA}$; $p=0.1450, t=1.497$, two-tailed unpaired $t$ test) or diestrus and proestrus (diestrus: $18.41 \pm 1.01 \mathrm{pA}$; proestrus: $15.99 \pm 0.87 \mathrm{pA}$; $p=0.0900, t=1.782$, two-tailed unpaired $t$ test).

Coordinated differences in $\mathrm{PV}^{+}$and sIPSC frequency across the estrous cycle point toward differences in the number or activity of $\mathrm{PV}^{+}$interneurons. A change in sIPSC frequency can be caused by a change of interneuron firing or GABA release. To narrow the options and remove interneuron firing activity as a factor, mIPSC frequency and amplitude were measured (with $1 \mu \mathrm{M}$ TTX; Fig. 6). There were significant sex differences in mIPSC frequency in LAT neurons, with a greater mIPSC frequency in females compared with males (Fig. 6 A, B; males: $1.29 \pm 0.29 \mathrm{~Hz}$, $n=10$ cells from 4 rats; females: $4.58 \pm 0.73 \mathrm{~Hz}, n=25$ cells from 9 rats; $p=0.0089, t=2.781$, two-tailed unpaired $t$ test). There was no significant difference in the frequency of mIPSCs across the estrous cycle in LAT neurons (Fig. $6 B$; diestrus: $5.14 \pm 0.92 \mathrm{~Hz}$, $n=13$ cells from 6 rats; proestrus: $3.43 \pm 0.64 \mathrm{~Hz}, n=14$ cells from 5 rats; $p=0.1346, t=1.546$, two-tailed unpaired $t$ test). No difference was observed in mIPSC amplitude between males and females (Fig. $6 B$, right; males: $13.33 \pm 1.62$ pA; females: $14.71 \pm$ $0.68 \mathrm{pA} ; p=0.3547, t=0.9388$, two-tailed unpaired $t$ test) or diestrous and proestrous groups (Fig. $6 B$, right; diestrus: $14.89 \pm$ $0.82 \mathrm{pA}$; proestrus: $14.54 \pm 1.08 \mathrm{pA} ; p=0.8010, t=0.2550$, two-tailed unpaired $t$ test).
While a sex difference in the frequency of mIPSCs recorded from BA neurons did not reach statistical significance (Fig. $6 D$; males: $1.77 \pm 0.33 \mathrm{~Hz}, n=10$ cells from 4 rats; females: $3.93 \pm$ $0.86 \mathrm{~Hz}, n=25$ cells from 8 rats; $p=0.1288, t=1.558$, two-tailed unpaired $t$ test), there were substantial differences across the estrous cycle. There was a greater frequency of mIPSCs in BA neurons during diestrus compared with proestrus (Fig. 6C,D; diestrus: $6.51 \pm 1.65 \mathrm{~Hz}, n=10$ cells from 4 rats; proestrus: $2.21 \pm 0.65 \mathrm{~Hz}, n=15$ cells from 4 rats; $p=0.0109, t=2.772$, two-tailed unpaired $t$ test). There was no significant difference in mIPSC amplitude between males and females (Fig. 6D, right; males: $12.20 \pm 0.55$; females: $13.89 \pm 0.51 ; p=0.0576, t=1.972$, two-tailed unpaired $t$ test) or diestrous and proestrous groups (Fig. $6 D$, right; diestrus: $14.58 \pm 0.72 \mathrm{pA}$; proestrus: $13.35 \pm 0.70$ $\mathrm{pA} ; p=0.2401, t=1.209$, two-tailed unpaired $t$ test). These results are consistent with sex differences in GABA release/synapse number in the LAT and BA. However, the results point to a shift in interneuron activity across the estrous cycle in LAT, but a shift in GABA release/synapse number and interneuron activity across the estrous cycle in BA.

To further test this working hypothesis, paired-pulse facilitation of IPSCs was measured in vitro and interneuron firing was measured in vivo. Paired-pulse ratio of evoked IPSCs $(50 \mathrm{~ms}$ interstimulus interval) was measured across the estrous cycle. There was a significant difference in the BA, where the pairedpulse ratio was lower in diestrus compared with proestrus (Fig. $7 B ; p=0.0319, t=2.300$; diestrus: $n=10$ cells from 5 rats; proestrus: $n=13$ cells from 6 rats; two-tailed unpaired $t$ test). 

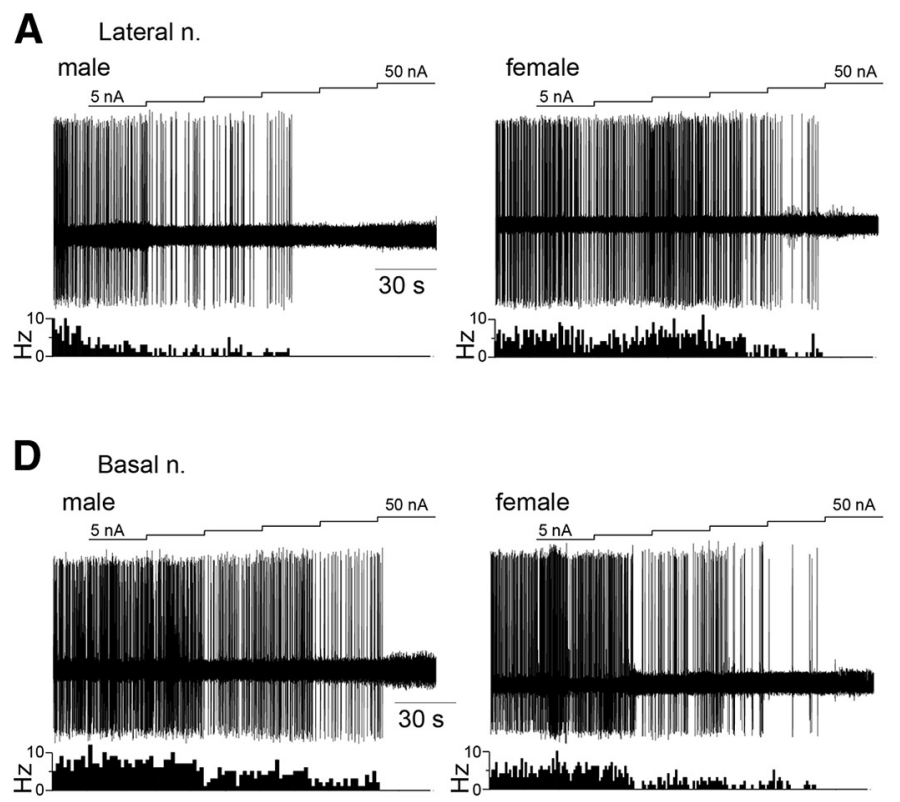

B
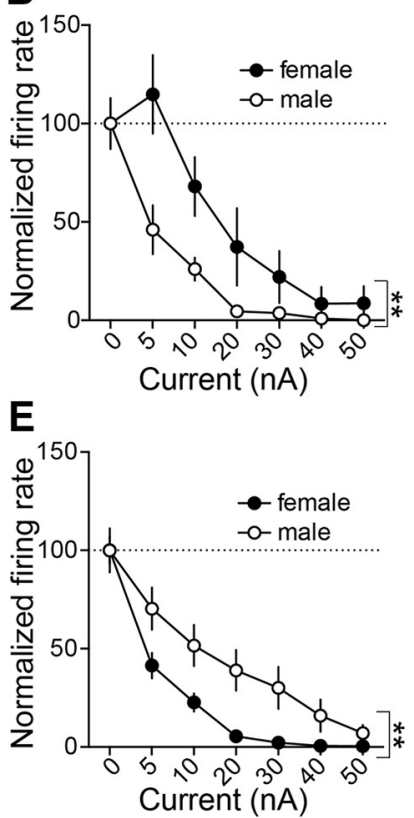

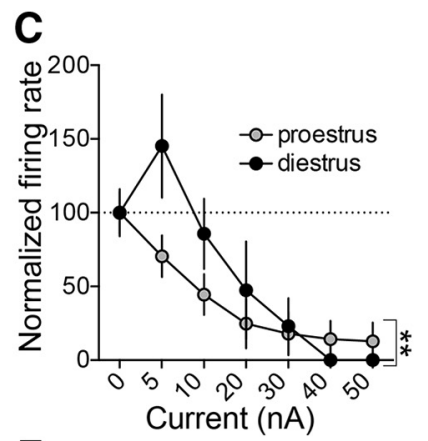

$\mathbf{F}$

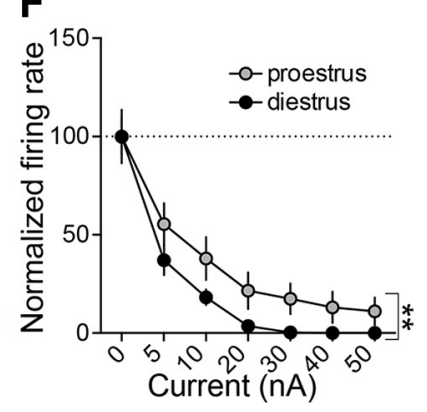

Figure 8. Opposite in vivo sensitivity to GABA across estrous females between LAT and BA. GABA was iontophoresed in ascending current, while neuronal firing was measured. $\boldsymbol{A}$, Representative traces of iontophoretic current applied to eject GABA (top), the neuronal response to GABA (middle), and a time histogram of the firing rate of LAT neurons recorded from a male (left) and female rat (right). $\boldsymbol{B}$, In LAT neurons, GABA was more effective in suppressing neuron firing in males compared with females ( $p<0.05$, two-way ANOVA). $\boldsymbol{C}$, GABA was also more effective in suppressing LAT neuron firing in proestrous females compared with diestrous females ( $p<0.05$, two-way ANOVA). $D$, Representative traces of iontophoretic current applied to eject GABA (top), the neuronal response to GABA (middle) and a time histogram of the firing rate of BA neurons recorded from a male (left) and a female (right) rat. $\boldsymbol{E}$, In contrast to $L A T$ neurons, $G A B A$ was more effective at suppressing the firing of BA neurons in females compared with males ( $p<0.05$, two-way ANOVA). $F$, Also in contrast to LAT neurons, GABA was more effective in suppressing BA neuron firing in diestrous compared with proestrous females ( $p<0.05$, two-way ANOVA). ${ }^{* *} p<0.05$, two-way ANOVA.

Along with the observed differences in MIPSC frequency, this is consistent with greater GABA release probability during diestrus. There was no significant difference in paired-pulse ratio in LAT neurons across the estrous cycle (Fig. $7 A ; p=0.5550, t=0.5990$; diestrus: $n=11$ cells from 5 rats; proestrus: $n=14$ cells from 6 rats; two-tailed unpaired $t$ test), consistent with LAT differences in sIPSCs due to interneuron activity, not GABA release.

A small number of neurons fit criteria for presumptive interneurons (Fig. 7C; it should be noted that the number of presumptive interneurons might not reflect the true proportion of interneurons in the BLA due to the tentative nature of their identification and attempts to isolate and record interneurons after the initial electrode track). There was a significant difference in the average firing rate of presumptive interneurons across the estrous cycle in the LAT, with a lower firing rate during proestrus (Fig. $7 \mathrm{D}, \mathrm{F}$; diestrus: $8.0 \pm 1.7 \mathrm{~Hz}, n=5$ cells in 5 rats; proestrus: $3.36 \pm 1.0 \mathrm{~Hz}, n=6$ cells in 6 rats; $p=0.0291, t=2.593$, two-tailed unpaired $t$ test). There were no significant differences in the firing rate of presumptive interneurons in the BA across the estrous cycle (Fig. $7 E, F$; diestrus: $7.3 \pm 2.0 \mathrm{~Hz}, n=6$ cells in 6 rats; proestrus: $4.4 \pm 1.4 \mathrm{~Hz}, n=6$ cells in 6 rats; $p=0.2547, t=$ 1.208 , two-tailed unpaired $t$ test). This is consistent with a shift in interneuron firing in the LAT contributing to a shift in sIPSCs across the estrous cycle, while a shift in GABA release contributes to a shift in sIPSCs in the BA.

\section{In vivo sensitivity to $G A B A$}

To test whether sex differences of GABAergic function in vivo can produce sex differences in BLA neuronal firing, postsynaptic responses to GABA were measured by GABA iontophoresis. Neurons were induced to fire at $5-10 \mathrm{~Hz}$ with iontophoretic glutamate. The effect of iontophoretic GABA on this firing was mea- sured. GABA suppressed the firing of BLA neurons (Fig. 8A,D). However, there were sex- and estrous-dependent differences in the ability of GABA to inhibit firing. In the LAT, GABA suppressed the firing of neurons in males more effectively than in females (Fig. $8 A, B$; main effect of sex: $p=0.0005, F_{(1,137)}=$ 12.87; males: $n=10$ cells in 7 rats; females: $n=13$ cells in 12 rats; two-way ANOVA). In addition, GABA was more effective in suppressing LAT neuron firing during proestrus compared with diestrus (Fig. $8 A, C$; main effect of estrous phase: $p=0.0495, F_{(1,73)}=$ 3.991; diestrus: $n=7$ cells in 6 rats; proestrus: $n=6$ cells in 6 rats; two-way ANOVA). A remarkably different pattern emerged in the BA, with main effects in the opposite direction as LAT. Thus, GABA suppressed the firing of BA neurons in females more effectively than in males (Fig. $8 D, E$; main effect of sex: $p<0.0001$, $F_{(1,210)}=23.02$; males: $n=11$ cells in 7 rats; females: $n=21$ cells in 13 rats; two-way ANOVA). Also opposite to LAT, GABA was more effective in suppressing BA neuron firing during diestrus compared with proestrus (Fig. 8D,F; main effect of estrous phase: $p=0.0006, F_{(1,133)}=12.32$; diestrus: $n=13$ cells in 7 rats; proestrus: $n=8$ cells in 6 rats; two-way ANOVA). These results demonstrate a change in the in vivo sensitivity to GABA across the estrous cycle that can work in parallel with the observed changes in GABA release and interneuron activity.

\section{Inhibition/excitation ratio}

While the in vitro and in vivo measures of glutamatergic and GABAergic function are internally consistent, the in vitro measures do not perfectly predict the in vivo firing. This led us to hypothesize that the absolute glutamatergic or GABAergic influence is not the most important factor to predict differences in neuronal firing. Rather, the relative balance between GABAergic 

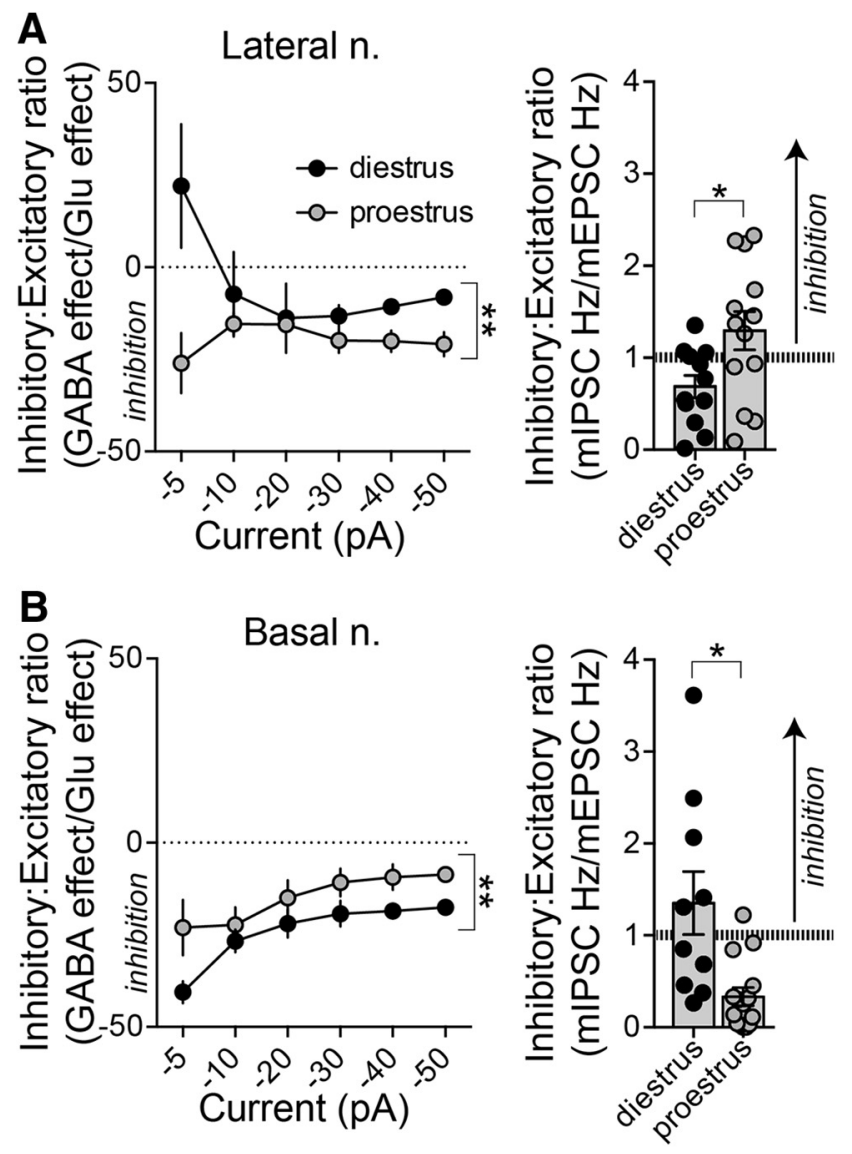

Figure 9. Opposite inhibition- excitation balance in LAT and BA across the estrous cycle. To examine the balance of glutamatergic and GABAergic function in our in vivo and in vitro measures, we compared the ratio of GABAergic inhibition to glutamatergic excitation. $A$, In the LAT, the balance was shifted toward greater in vivo inhibition during proestrus compared with diestrus. Proestrous females had a higher inhibitory/excitatory ratio in LAT neurons both in vivo (left; $p<0.05$, two-way ANOVA) and in vitro (right; $p<0.05$, two-tailed unpaired $t$ test). $\boldsymbol{B}$, In the $B A$ nucleus, diestrous females had a greater inhibitory/excitatory ratio both in vivo (left; $p<$ 0.05 , two-way ANOVA) and in vitro (right; $p<0.05$, two-tailed unpaired $t$ test). ${ }^{*} p<0.05$, two-tailed unpaired $t$ test; ${ }^{* *} p<0.05$, two-way ANOVA.

inhibition and glutamatergic excitation could be key (ArrudaCarvalho and Clem, 2014). This was measured as the ratio of the effects of iontophoretic GABA/iontophoretic glutamate on in vivo neuronal firing and the in vitro ratio of mIPSCs to mEPSCs.

In the LAT, the inhibitory/excitatory ratio was shifted toward stronger inhibition during proestrus, when measured as either the in vivo balance (Fig. $9 A$, left; main effect of estrous phase: $p=$ $0.0024, F_{(1,62)}=10.06$, two-way ANOVA) or the in vitro balance (Fig. 9A, right; $p=0.0212, t=2.472$, two-tailed unpaired $t$ test). In contrast, in the BA, the inhibitory/excitatory ratio was shifted toward stronger inhibition during diestrus, when measured as either the in vivo balance (Fig. 9B, left; main effect of estrous phase: $p<0.0001, F_{(1,114)}=19.80$, two-way ANOVA) or the in vitro balance (Fig. $9 B$, right; $p=0.0026, t=3.378$, two-tailed unpaired $t$ test). Thus, in vivo and in vitro measures of the inhibitory-excitatory balance are mutually predictive across the estrous cycle and reveal an opposite shift between the LAT and BA.

\section{LAT- and BA-dependent fear behavior}

Learned fear behavior depends strongly on the BLA, with the LAT contributing to cued fear and the BA contributing to contextual fear. These behaviors, and in particular their extinction, are sensitive to shifts in excitatory and inhibitory drive (Harris and Westbrook, 1998; Akirav et al., 2006; Ehrlich et al., 2009; Makkar et al., 2010; Heaney et al., 2012; Cho et al., 2013; Wolff et al., 2014). Because our data above demonstrate a shift in the inhibitory-excitatory balance across the estrous cycle, but in opposite directions in the LAT and BA, we tested whether LAT- and BAdependent fear extinction displays opposite estrous cyclicity that mirrors the inhibitory-excitatory balance shifts.

There were no significant differences in the acquisition of fear compared across the estrous cycle (Fig. 10B; diestrus: $n=17$; proestrus: $n=15$; main effect of estrous phase: $p=0.163, F_{(1,30)}=$ 2.058; estrous $\times$ trial interaction: $p=0.370, F_{(5,150)}=1.088$, two-way RM-ANOVA). The acquisition of extinction of conditioned freezing to a cue was measured in a novel chamber. Diestrous rats displayed significantly slower acquisition of extinction to the cue compared with proestrous rats (Fig. 10C; main effect of estrous phase: $p=0.0498, F_{(1,30)}=4.180$; estrous phase $\times$ trial interaction: $p=0.1468, F_{(15,450)}=1.392$; diestrus: $n=17$; proestrus: $n=15$; two-way RM-ANOVA). It is possible that the difference in fear extinction across the estrous cycle could simply be due to differences in the propensity to freeze. Emerging evidence indicates that there may be sex differences in the predominant manner by which male and female rats express fear memory (Gruene et al., 2015). To examine this, darting behavior was quantified during the expression of cued fear (Gruene et al., 2015). There was minimal darting in these rats ( 0 of 6 male rats; 1 of 29 female rats; in females: 1 of 14 diestrus rats; 0 of 15 proestrus rats), requiring another approach to assess active cued conditioned responses. The very low level of darting observed during extinction may be due to a smaller number of conditioned stimulus-unconditioned stimulus conditioning trials, lower shock intensity, and differences in the size of the chambers used. To further test for differences in expression that may be due to differences in predominant activity instead of fear, we examined the extinction of active avoidance, in which learned behavior is expressed as movement instead of freezing. Diestrous and proestrous rats displayed similar learning behavior (days 1-3). However, there was a significant difference in extinction behavior (test day). Diestrous females displayed slower extinction compared with proestrous females (Fig. 10C; estrous phase $\times$ trial block interaction: $p=0.0365, F_{(5,60)}=2.559$; diestrus: $n=9$; proestrus: $n=8$; two-way RM-ANOVA). These results parallel the slower extinction of cued-evoked conditioned freezing in diestrous females.

While cued freezing and its extinction rely on the LAT, contextual freezing and its extinction may rely more heavily on the BA (Calandreau et al., 2005; Onishi and Xavier, 2010; Orsini et al., 2011; Vlachos et al., 2011). The acquisition of the extinction of conditioned freezing to the context was measured across time. Proestrous females displayed slower acquisition of extinction to context compared with diestrous females (Fig. 10D; estrous phase $\times$ trial block interaction: $p<0.0001, F_{(11,396)}=4.914$; diestrus: $n=20$; proestrus: $n=18$; two-way RM-ANOVA), which is opposite to the pattern observed with cued fear. These results demonstrate a functional shift in LAT- and BA-dependent behaviors across the estrous cycle that mirrors the shift in the inhibition-excitation balance.

There were no significant differences between male and female rats in the acquisition of fear (Fig. 11A; main effect of sex: $p=0.491, F_{(1,36)}=0.485$; sex $\times$ trial interaction: $p=0.964$, $F_{(5,180)}=0.1956 ; n=11$ male rats; $n=32$ female rats; two-way RM-ANOVA). However, female rats demonstrated more robust 

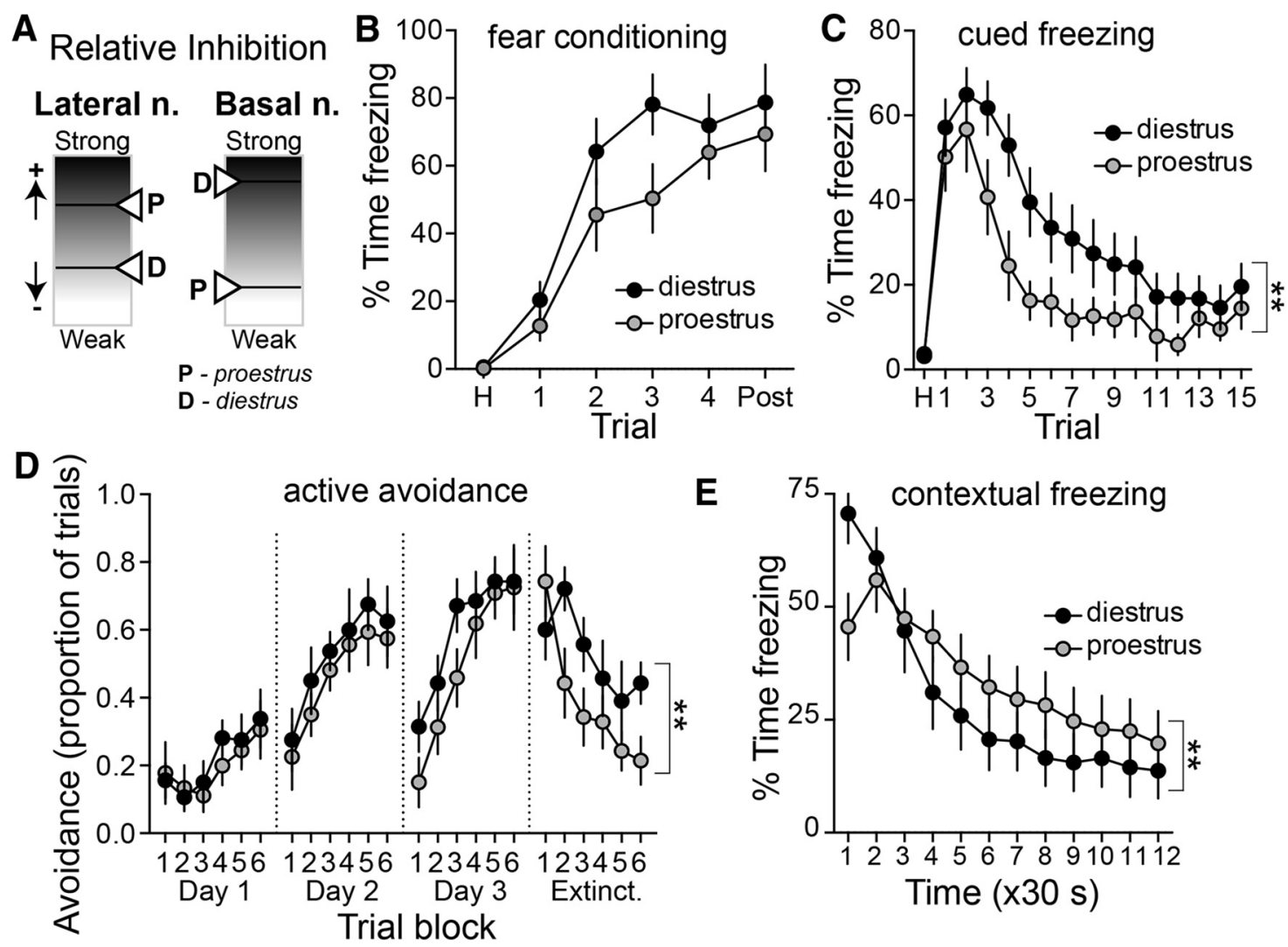

Figure 10. Shift between LAT and BA function across the estrous cycle. $A$, Schematic illustration of the opposite effects of estrous cyclicity on relative inhibition in the LAT and BA. B, Cued fear conditioning of a tone paired with a footshock led to gradual acquisition of freezing. There was no significant difference between diestrus $(n=17)$ and proestrus $(n=15)$ in the freezing during repeated tone-footshock conditioning trials ( $p>0.05$, two-way RM-ANOVA). C, Acquisition of extinction of conditioned freezing to a cue was measured as the reduced conditioned freezing across nonreinforced trials on the testing day. The acquisition of extinction to the cue was significantly slower in diestrous compared with proestrous females ( $p<0.05$, two-way RM-ANOVA). D, Extinction of active avoidance was measured as the reduced avoidance response to a cue. Diestrous and proestrous females displayed similar learning behavior (days 1-3); however, diestrous females displayed slower extinction compared with proestrous females ( $p<0.05$, two-way RM-ANOVA). $\boldsymbol{E}$, Acquisition of the extinction of contextual fear was measured as reduced conditioned freezing in a footshock-paired context over time. Proestrous females displayed slower acquisition of extinction compared with diestrous females $\left(p<0.05\right.$, two-way RM-ANOVA). ${ }^{* *} p<0.05$, two-way RM-ANOVA.

initial expression of conditioned fear (Fig. 11B; first three trials; freezing during the first three trials collapsed: females: $56.6 \pm$ $2.8 \%$ of time freezing; males: $46.0 \pm 2.8 \%$ of time freezing; $p=$ $0.042, t=2.10, \mathrm{df}=41 ; n=11$ male rats; $n=32$ female rats; two-tailed unpaired $t$ test), but there was no evidence of sex differences in the acquisition of extinction (Fig. $11 B$; main effect of sex: $p=0.493, F_{(1,41)}=0.478$; sex $\times$ trial interaction: $p=0.979$, $F_{(15,615)}=0.400 ; n=11$ male rats; $n=32$ female rats; two-way RM-ANOVA). In the active avoidance task, a greater initial expression of active avoidance was observed in female rats (Fig. $11 D$, trial block 1, extinction day; main effect of sex: $p=0.0490$, $F_{(1,20)}=4.395 ; n=8$ male rats; $n=17$ female rats; two-way RM-ANOVA). However, when this difference in initial expression was taken into account, there was no significant difference in the extinction of active avoidance (Fig. $11 D$, right; main effect of sex: $p=0.982, F_{(1,20)}=0.0005$, two-way RM-ANOVA). In the expression of contextual fear, there were hints toward an initially more robust expression in female rats (Fig. 11C; freezing during the first two segments collapsed; females: $58.1 \pm 1.5 \%$; males: $47.5 \pm 3.3 \%, p=0.0023, t=3.22$, df $=47$; males: $n=11$ rats; females, $n=38$ rats; two-tailed unpaired $t$ test), but no significant evidence for a difference in extinction (Fig. 11C; main effect of sex: $p=0.650, F_{(1,46)}=0.208$; sex $\times$ trial interaction: $p=0.737$, $F_{(11,506)}=0.702$, two-way RM-ANOVA).

\section{Discussion}

In rodent limbic regions, such as hippocampus and prefrontal cortex, there are parallel differences in neuronal morphology and hippocampal- or prefrontal-dependent cognitive behaviors between males and females and across the estrous cycle (Gould et al., 1990; Woolley et al., 1990; Kolb and Stewart, 1991; Woolley and McEwen, 1992; Markham and Juraska, 2002; Park et al., 2008; Garrett and Wellman, 2009; Baran et al., 2010; Fenton et al., 2014). Emotion-related behaviors can also depend on sex and estrous cycle phase; differences in the amygdala likely contribute. Although the characteristics of BLA neurons in males have been studied previously (Rosenkranz and Grace, 1999, 2001, 2002; Likhtik et al., 2006; Zhang and Rosenkranz, 2012), any sex differences in BLA neuronal activity were unknown. To our knowledge, this is the first study to demonstrate that BLA neurons are more active in females compared with males.

The greater BLA neuronal activity in females is observed in parallel with higher glutamatergic drive in the LAT and BA. Sex differences in GABAergic regulation may also contribute; however, the current results offer only mixed evidence in support of this (Tables 1,2). While we found a higher number of spines in the BA of female rats, which is consistent with a previous finding of higher presynaptic protein synaptophysin in the BA of female 

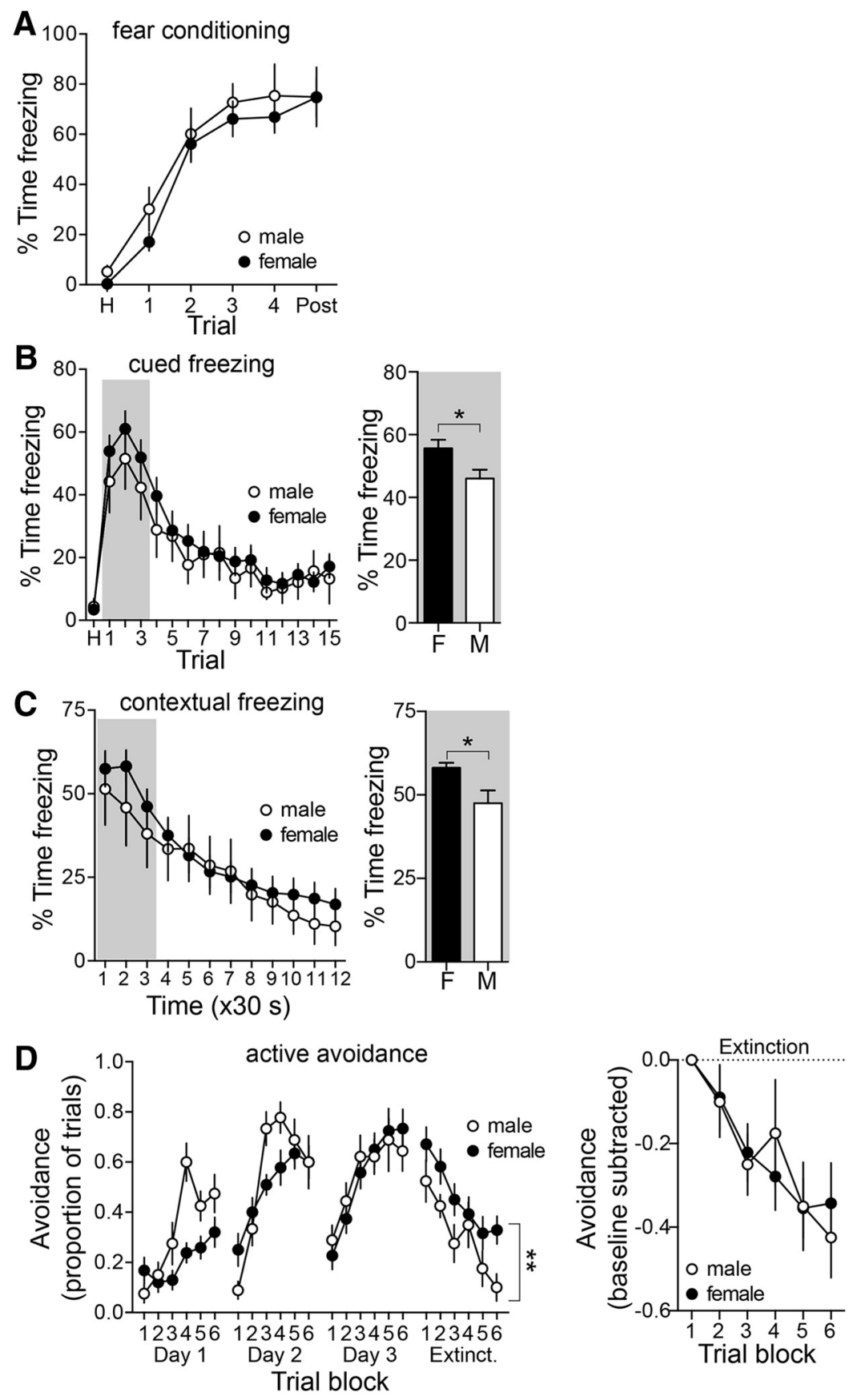

Figure 11. Sex differences in the expression of conditioned fear. $\boldsymbol{A}$, Fear conditioning was measured during acquisition in male and female rats. Acquisition of conditioned fear was similar in male and female rats ( $p>0.05$, two-way RMANOVA). $\boldsymbol{B}$, Conditioned freezing to a cue was measured in a novel context over the course of repeated trials. There were no sex differences overall in conditioned freezing (left; $p>0.05$, two-way RM-ANOVA; male $n=11$; female $n=32$ ). However, when assessing the initial expression of conditioned cued freezing, before significant extinction of the conditioned response, females displayed greater conditioned freezing (freezing during the first three trials collapsed; $p<0.05$, two-tailed unpaired $t$ test). $C$, Conditioned freezing to a context was measured in the conditioned context over time. There were no sex differences overall in conditioned freezing (left; $p>0.05$, two-way RM-ANOVA; males, $n=11$; females, $n=$ 38). However, when assessing the initial expression of conditioned contextual freezing, before significant extinction of the conditioned response, females displayed greater conditioned freezing (freezing during the first two segments collapsed; $p<0.05$, two-tailed unpaired $t$ test. $\boldsymbol{D}$, The expression of active avoidance during the extinction session was significantly greater in female rats $(p<0.05$, two-way RM-ANOVA). The greater expression in female rats throughout the extinction session could be due to higher initial expression or slower extinction. However, when normalized by the initial expression (trial block 1), there was no significant difference between males and females across extinction blocks ( $p>0.05$, two-way RM-ANOVA). ${ }^{*} p<0.05$, two-tailed unpaired $t$ test; ${ }^{* *} p<0.05$, two-way RM-ANOVA. rats (Carvalho-Netto et al., 2011), a different study found lower spine densities in female rats (Rubinow et al., 2009). A difference in approach to quantifying spines may have contributed to these disparate findings.

The current study found a shift of BLA activity over the course of the $4 \mathrm{~d}$ estrous cycle. LAT neuronal firing was greater during diestrus, while BA neuronal firing was higher in proestrus. However, a shift in neither glutamatergic nor GABAergic measures singly could adequately account for this. The pattern of changes in glutamatergic and GABAergic measures across the estrous cycle can be most readily distilled into a shift in the balance between inhibition and excitation. This balance shifts across the estrous cycle such that the LAT is relatively less inhibited during diestrus, corresponding to higher in vivo LAT neuron firing, while the BA is less inhibited during proestrus, corresponding to higher BA neuron firing. One caveat is that the inhibition (mIPSCs) and excitation (mEPSCs) measured in vitro were from different sets of neurons. While excitatory and inhibitory measures were obtained from the same neurons in vivo, and care was taken to record both inhibition and excitation from the same animals in vitro, recording these measures from different neurons in vitro weakens the interpretation. Future experiments will explore whether factors that translate synaptic integration into neuronal firing (e.g., neuronal excitability, membrane resistance) contribute to the effects observed here.

$\mathrm{PV}^{+}$interneurons are the predominant interneuron in the BLA and exert potent effects on BLA output (Woodruff and Sah, 2007; Wolff et al., 2014). However, it is possible that other GABAergic interneuron populations, such as calbindin- or calretinin-expressing interneurons (Kemppainen and Pitkänen, 2000; McDonald and Mascagni, 2001; Spampanato et al., 2011), may also shift across the estrous cycle (Micevych et al., 1988). $\mathrm{PV}^{+}$interneurons in several brain regions, including the amygdala, express estrogen receptors (Blurton-Jones and Tuszynski, 2002), and estradiol can inhibit the activity of GABA interneurons (Rudick and Woolley, 2001). The expression of PV is dependent upon neuronal activity (Carder et al., 1996; Philpot et al., 1997; Patz et al., 2004; Jiao et al., 2006). This would suggest that the relatively rapid fluctuation of $\mathrm{PV}^{+}$cell number across the estrous cycle likely represents alterations in PV expression that parallel changes of interneuron activity. There is a general in- 
Table 1. Summary of sex differences

\begin{tabular}{|c|c|c|c|c|}
\hline & \multicolumn{2}{|c|}{ Lateral nucleus } & \multicolumn{2}{|c|}{ Basal nucleus } \\
\hline & Male & Female & Male & Female \\
\hline Firing rate & + & +++ & + & +++ \\
\hline \multicolumn{5}{|c|}{ Excitatory measures } \\
\hline Spines & + & ++ & + & ++ \\
\hline EPSC & + & ++ & + & ++ \\
\hline Glutamate & + & ++ & + & ++ \\
\hline \multicolumn{5}{|c|}{ Inhibitory measures } \\
\hline PV & ++ & ++ & ++ & + \\
\hline SIPSC & + & ++ & + & ++ \\
\hline mIPSC & + & ++ & + & ++ \\
\hline GABA & +++ & ++ & ++ & +++ \\
\hline
\end{tabular}

The relative amplitude of measures are presented on a grayscale. Note that females tend to have stronger excitatory influences across measures in the LAT and BA. Number of + symbols indicates amplitude of measure.

Table 2. Summary of estrous differences

\begin{tabular}{lll}
\hline & Lateral nucleus & Basal nucleus \\
\hline Firing rate & $\mathrm{Di}$ & Pro \\
Excitatory measures & $=$ & $\mathrm{Di}$ \\
$\quad$ Spines & $=$ & $\mathrm{Di}$ \\
mEPSC & $\mathrm{Di}$ & Pro \\
Glutamate & & \\
Inhibitory measures & $\mathrm{Di}$ & $\mathrm{Di}$ \\
PV & $\mathrm{Di}$ & $\mathrm{Di}$ \\
SIPSC & $=$ & $\mathrm{Di}$ \\
mIPSC & $=$ & Pro \\
PP ratio & $\mathrm{Di}$ & $=$ \\
Interneuron & Pro & $\mathrm{Di}$ \\
GABA & &
\end{tabular}

Measured aspects of excitatory and inhibitory function were compiled. Estrous cycle phase with the greater measure is indicated for the lateral nucleus and basal nucleus. Di, Diestrus; Pro, proestrus; PP, paired-pulse; = denotes no significant difference.

crease of $\mathrm{PV}^{+}$and sIPSCs during diestrus in both LAT and BA. This increased inhibition is associated with higher interneuron firing in the LAT, but enhanced GABA release in the BA. This indicates that different mechanisms regulate the shifts of GABAergic inhibition across the estrous cycle, leading to differences in the functional expression of the inhibition.

Previous work in awake male animals demonstrates that greater BLA neuron activity is associated with greater fear conditioning (Maren, 2000; Paré and Collins, 2000; Pelletier et al., 2005). Considering the faster BLA neuron firing rates in females from our experiments, one might expect that females would show greater performance in BLA-dependent behaviors compared with males. However, the literature shows mixed results. For example, females learn eye-blink conditioning, a BLA-sensitive behavior (Waddell et al., 2008) faster than males (Wood and Shors, 1998), and there are reports of more robust freezing to a conditioned cue (Aguilar et al., 2003; Wiltgen et al., 2005). In contrast, females express less contextual fear conditioning than males (Maren et al., 1994; Gupta et al., 2001; Wiltgen et al., 2001). However, other studies diverge from this pattern (Aguilar et al., 2003). One way to begin to untangle the mixed findings is by separately considering behaviors that rely on the LAT or BA. In addition, studies often collapse fear expression over trials/time into single data points, which may inadvertently mask differences in the expression and extinction of fear. Furthermore, estrogens play a role in the sex-specific difference in BLA-dependent behavior performance (Maren et al., 1994; Gupta et al., 2001), with potentially different effects on cued and contextual fear learning (Barha et al., 2010; McDermott et al., 2015). In the current study, there was evidence for greater expression of conditioned fear in female rats, with little evidence of differences in the acquisition or extinction of fear. This was observed as increased LAT-dependent cued freezing and BA-dependent contextual freezing in females. This parallels the greater excitatory drive of both LAT and BA neurons in females. This effect was seen with both passive (freezing) and active (active avoidance) conditioned responses.

Previous studies demonstrate less robust extinction of contextual (Baran et al., 2009; Matsuda et al., 2015) and cued fear in females (Baran et al., 2009). However, within females, extinction fluctuates across the estrous cycle or in response to manipulations of estradiol. Proestrus, when estradiol levels are high, is associated with faster extinction of cued fear (Milad et al., 2009), whereas low estradiol is associated with less extinction of cued fear (Graham and Milad, 2013; Rey et al., 2014), and estrogen agonists can facilitate consolidation of extinction of cued fear (Zeidan et al., 2011). In contrast, estrogen agonists can cause slower extinction to context (McDermott et al., 2015), while low estrogen levels can also slow the extinction of contextual fear (Gupta et al., 2001). GABAergic inhibition is particularly important in fear extinction (Chhatwal et al., 2005; Polepalli et al., 2010; Trouche et al., 2013; Wolff et al., 2014). Our results demonstrate inhibitory-excitatory balance shifts; when the inhibition is relatively higher in the LAT during proestrus, there is a shift toward better extinction of LAT-mediated cued fear. During diestrus, when inhibition is relatively higher in the BA, there is better BA-mediated extinction of contextual fear. This result provides a simple construct for understanding the effects of the estrous cycle and of estrogen on fear extinction.

A handful of studies demonstrate sex differences of human amygdala activation, including three meta-analyses of the response to facial expressions (Sergerie et al., 2008; Fusar-Poli et al., 2009; Filkowski et al., 2017). Several studies have found sex differences in the laterality of amygdala activation (Cahill et al., 2004) or functional connectivity to other brain regions (Kilpatrick et al., 2006; Engman et al., 2016; Wu et al., 2016), while others find greater amygdala activation in men in response to positive valenced and sexual stimuli (Hamann et al., 2004; Stevens and Hamann, 2012) but greater amygdala activation in women in response to negative valenced stimuli (Wrase et al., 2003; Hofer et al., 2006; Stevens and Hamann, 2012; Mareckova et al., 2016) or during non-emotion-related tasks (Hill et al., 2014), despite evidence of similar anatomical size (Marwha et al., 2017). Furthermore, major affective disorders that are more common in women (e.g., depression, anxiety, post-traumatic stress disorder) are associated with hyperactivation of the BLA (Sheline et al., 2001; Etkin and Wager, 2007; Victor et al., 2010; Hattingh et al., 2012; Sartory et al., 2013). Amygdala activity shows estrus-related cyclicity (Goldstein et al., 2005b; Andreano and Cahill, 2009; Hwang et al., 2015) in parallel with aspects of emotional memory (Gasbarri et al., 2008; Milad et al., 2010; Zeidan et al., 2011; Nielsen et al., 2013; Bayer et al., 2014; Wegerer et al., 2014; Pompili et al., 2016). In addition, there is evidence that the menstrual cycle and periods of sex hormone fluctuation can influence depressive and anxiety symptoms in humans (Dean and Kendell, 1981; Rapkin et al., 2002; Vesga-López et al., 2008; Schmidt and Rubinow, 2009; van Veen et al., 2009; Bryant et al., 2011). While sociocultural factors surely influence human emotion, our results begin to establish a framework that can help to clarify the link between amygdala activity and amygdala-dependent behaviors in females. Specifically, a shift in the inhibition-excitation balance across BLA nuclei may lead to a switch in the balance between salience of specific cue or contextual drivers of emotion. This 
framework may in turn provide insight into differences in the expression of depression and anxiety symptoms in females.

\section{References}

Aguilar R, Gil L, Gray JA, Driscoll P, Flint J, Dawson GR, Giménez-Llort L, Escorihuela RM, Fernández-Teruel A, Tobeña A (2003) Fearfulness and sex in $\mathrm{f} 2$ roman rats: males display more fear though both sexes share the same fearfulness traits. Physiol Behav 78:723-732. CrossRef Medline

Akirav I, Raizel H, Maroun M (2006) Enhancement of conditioned fear extinction by infusion of the GABA(A) agonist muscimol into the rat prefrontal cortex and amygdala. Eur J Neurosci 23:758-764. CrossRef Medline

Andreano JM, Cahill L (2009) Sex influences on the neurobiology of learning and memory. Learn Mem 16:248-266. CrossRef Medline

Arruda-Carvalho M, Clem RL (2014) Pathway-selective adjustment of prefrontal-amygdala transmission during fear encoding. J Neurosci 34: 15601-15609. CrossRef Medline

Baran SE, Armstrong CE, Niren DC, Hanna JJ, Conrad CD (2009) Chronic stress and sex differences on the recall of fear conditioning and extinction. Neurobiol Learn Mem 91:323-332. CrossRef Medline

Baran SE, Armstrong CE, Niren DC, Conrad CD (2010) Prefrontal cortex lesions and sex differences in fear extinction and perseveration. Learn Mem 17:267-278. CrossRef Medline

Barha CK, Dalton GL, Galea LA (2010) Low doses of 17alpha-estradiol and 17beta-estradiol facilitate, whereas higher doses of estrone and 17alphaand 17beta-estradiol impair, contextual fear conditioning in adult female rats. Neuropsychopharmacology 35:547-559. CrossRef Medline

Bayer J, Schultz H, Gamer M, Sommer T (2014) Menstrual-cycle dependent fluctuations in ovarian hormones affect emotional memory. Neurobiol Learn Mem 110:55-63. CrossRef Medline

Becker JB, Arnold AP, Berkley KJ, Blaustein JD, Eckel LA, Hampson E, Herman JP, Marts S, Sadee W, Steiner M, Taylor J, Young E (2005) Strategies and methods for research on sex differences in brain and behavior. Endocrinology 146:1650-1673. CrossRef Medline

Blurton-Jones M, Tuszynski MH (2002) Estrogen receptor-beta colocalizes extensively with parvalbumin-labeled inhibitory neurons in the cortex, amygdala, basal forebrain, and hippocampal formation of intact and ovariectomized adult rats. J Comp Neurol 452:276-287. CrossRef Medline

Brinley-Reed M, Mascagni F, McDonald AJ (1995) Synaptology of prefrontal cortical projections to the basolateral amygdala: an electron microscopic study in the rat. Neurosci Lett 202:45-48. CrossRef Medline

Bryant RA, Felmingham KL, Silove D, Creamer M, O’Donnell M, McFarlane AC (2011) The association between menstrual cycle and traumatic memories. J Affect Disord 131:398-401. CrossRef Medline

Cahill L, Uncapher M, Kilpatrick L, Alkire MT, Turner J (2004) Sex-related hemispheric lateralization of amygdala function in emotionally influenced memory: an FMRI investigation. Learn Mem 11:261-266. CrossRef Medline

Calandreau L, Desmedt A, Decorte L, Jaffard R (2005) A different recruitment of the lateral and basolateral amygdala promotes contextual or elemental conditioned association in pavlovian fear conditioning. Learn Mem 12:383-388. CrossRef Medline

Canli T, Desmond JE, Zhao Z, Gabrieli JD (2002) Sex differences in the neural basis of emotional memories. Proc Natl Acad Sci U S A 99:1078910794. CrossRef Medline

Carder RK, Leclerc SS, Hendry SH (1996) Regulation of calcium-binding protein immunoreactivity in GABA neurons of macaque primary visual cortex. Cereb Cortex 6:271-287. CrossRef Medline

Carvalho-Netto EF, Myers B, Jones K, Solomon MB, Herman JP (2011) Sex differences in synaptic plasticity in stress-responsive brain regions following chronic variable stress. Physiol Behav 104:242-247. CrossRef Medline

Chhatwal JP, Myers KM, Ressler KJ, Davis M (2005) Regulation of gephyrin and $\mathrm{GABA}_{\mathrm{A}}$ receptor binding within the amygdala after fear acquisition and extinction. J Neurosci 25:502-506. CrossRef Medline

Cho JH, Deisseroth K, Bolshakov VY (2013) Synaptic encoding of fear extinction in MPFC-amygdala circuits. Neuron 80:1491-1507. CrossRef Medline

Cooke BM (2006) Steroid-dependent plasticity in the medial amygdala. Neuroscience 138:997-1005. CrossRef Medline
Cooke BM, Woolley CS (2005) Sexually dimorphic synaptic organization of the medial amygdala. J Neurosci 25:10759-10767. CrossRef Medline

Cooke BM, Woolley CS (2009) Effects of prepubertal gonadectomy on a male-typical behavior and excitatory synaptic transmission in the amygdala. Dev Neurobiol 69:141-152. CrossRef Medline

Cooke BM, Breedlove SM, Jordan CL (2003) Both estrogen receptors and androgen receptors contribute to testosterone-induced changes in the morphology of the medial amygdala and sexual arousal in male rats. Horm Behav 43:336-346. CrossRef Medline

Cooke BM, Stokas MR, Woolley CS (2007) Morphological sex differences and laterality in the prepubertal medial amygdala. J Comp Neurol 501: 904-915. CrossRef Medline

Dean C, Kendell RE (1981) The symptomatology of puerperal illnesses. Br J Psychiatry 139:128-133. CrossRef Medline

Ehrlich I, Humeau Y, Grenier F, Ciocchi S, Herry C, Lüthi A (2009) Amygdala inhibitory circuits and the control of fear memory. Neuron 62:757-771. CrossRef Medline

Eliot L, Richardson SS (2016) Sex in context: limitations of animal studies for addressing human sex/gender neurobehavioral health disparities. J Neurosci 36:11823-11830. CrossRef Medline

Engman J, Linnman C, Van Dijk KR, Milad MR (2016) Amygdala subnuclei resting-state functional connectivity sex and estrogen differences. Psychoneuroendocrinology 63:34-42. CrossRef Medline

Etkin A, Wager TD (2007) Functional neuroimaging of anxiety: a metaanalysis of emotional processing in PTSD, social anxiety disorder, and specific phobia. Am J Psychiatry 164:1476-1488. CrossRef Medline

Farb C, Aoki C, Milner T, Kaneko T, LeDoux J (1992) Glutamate immunoreactive terminals in the lateral amygdaloid nucleus: a possible substrate for emotional memory. Brain Res 593:145-158. CrossRef Medline

Fenton GE, Pollard AK, Halliday DM, Mason R, Bredy TW, Stevenson CW (2014) Persistent prelimbic cortex activity contributes to enhanced learned fear expression in females. Learn Mem 21:55-60. CrossRef Medline

Filkowski MM, Olsen RM, Duda B, Wanger TJ, Sabatinelli D (2017) Sex differences in emotional perception: meta analysis of divergent activation. Neuroimage 147:925-933. CrossRef Medline

Floresco SB, Grace AA (2003) Gating of hippocampal-evoked activity in prefrontal cortical neurons by inputs from the mediodorsal thalamus and ventral tegmental area. J Neurosci 23:3930-3943. Medline

Frank E, Carpenter LL, Kupfer DJ (1988) Sex differences in recurrent depression: are there any that are significant? Am J Psychiatry 145:41-45. CrossRef Medline

Fusar-Poli P, Placentino A, Carletti F, Landi P, Allen P, Surguladze S, Benedetti F, Abbamonte M, Gasparotti R, Barale F, Perez J, McGuire P, Politi P (2009) Functional atlas of emotional faces processing: a voxel-based meta-analysis of 105 functional magnetic resonance imaging studies. J Psychiatry Neurosci 34:418-432. Medline

Garrett JE, Wellman CL (2009) Chronic stress effects on dendritic morphology in medial prefrontal cortex: sex differences and estrogen dependence. Neuroscience 162:195-207. CrossRef Medline

Gasbarri A, Pompili A, d'Onofrio A, Cifariello A, Tavares MC, Tomaz C (2008) Working memory for emotional facial expressions: role of the estrogen in young women. Psychoneuroendocrinology 33:964-972. CrossRef Medline

Goldstein JM, Jerram M, Poldrack R, Anagnoson R, Breiter HC, Makris N, Goodman JM, Tsuang MT, Seidman LJ (2005a) Sex differences in prefrontal cortical brain activity during fMRI of auditory verbal working memory. Neuropsychology 19:509-519. CrossRef Medline

Goldstein JM, Jerram M, Poldrack R, Ahern T, Kennedy DN, Seidman LJ, Makris N (2005b) Hormonal cycle modulates arousal circuitry in women using functional magnetic resonance imaging. J Neurosci 25: 9309-9316. CrossRef Medline

Gould E, Woolley CS, Frankfurt M, McEwen BS (1990) Gonadal steroids regulate dendritic spine density in hippocampal pyramidal cells in adulthood. J Neurosci 10:1286-1291. Medline

Graham BM, Milad MR (2013) Blockade of estrogen by hormonal contraceptives impairs fear extinction in female rats and women. Biol Psychiatry 73:371-378. CrossRef Medline

Gruene TM, Flick K, Stefano A, Shea SD, Shansky RM (2015) Sexually divergent expression of active and passive conditioned fear responses in rats. Elife 4:e11352. CrossRef Medline

Gupta RR, Sen S, Diepenhorst LL, Rudick CN, Maren S (2001) Estrogen modulates sexually dimorphic contextual fear conditioning and hip- 
pocampal long-term potentiation (ltp) in rats(1). Brain Res 888:356-365. CrossRef Medline

Hamann S, Herman RA, Nolan CL, Wallen K (2004) Men and women differ in amygdala response to visual sexual stimuli. Nat Neurosci 7:411-416. CrossRef Medline

Harris JA, Westbrook RF (1998) Evidence that GABA transmission mediates context-specific extinction of learned fear. Psychopharmacology (Berl) 140:105-115. CrossRef Medline

Hattingh CJ, Ipser J, Tromp SA, Syal S, Lochner C, Brooks SJ, Stein DJ (2012) Functional magnetic resonance imaging during emotion recognition in social anxiety disorder: an activation likelihood meta-analysis. Front Hum Neurosci 6:347. CrossRef Medline

Heaney CF, Bolton MM, Murtishaw AS, Sabbagh JJ, Magcalas CM, Kinney JW (2012) Baclofen administration alters fear extinction and GABAergic protein levels. Neurobiol Learn Mem 98:261-271. CrossRef Medline

Hill AC, Laird AR, Robinson JL (2014) Gender differences in working memory networks: a brainmap meta-analysis. Biol Psychol 102:18-29. CrossRef Medline

Hofer A, Siedentopf CM, Ischebeck A, Rettenbacher MA, Verius M, Felber S, Fleischhacker WW (2006) Gender differences in regional cerebral activity during the perception of emotion: a functional MRI study. Neuroimage 32:854-862. CrossRef Medline

Hwang MJ, Zsido RG, Song H, Pace-Schott EF, Miller KK, Lebron-Milad K, Marin MF, Milad MR (2015) Contribution of estradiol levels and hormonal contraceptives to sex differences within the fear network during fear conditioning and extinction. BMC Psychiatry 15:295. CrossRef Medline

Jiao Y, Zhang C, Yanagawa Y, Sun QQ (2006) Major effects of sensory experiences on the neocortical inhibitory circuits. J Neurosci 26:8691-8701. CrossRef Medline

Johnston AL, File SE (1991) Sex differences in animal tests of anxiety. Physiol Behav 49:245-250. CrossRef Medline

Kemppainen S, Pitkänen A (2000) Distribution of parvalbumin, calretinin, and calbindin- $\mathrm{d}(28 \mathrm{k})$ immunoreactivity in the rat amygdaloid complex and colocalization with gamma-aminobutyric acid. J Comp Neurol 426: 441-467. CrossRef Medline

Kilpatrick LA, Zald DH, Pardo JV, Cahill LF (2006) Sex-related differences in amygdala functional connectivity during resting conditions. Neuroimage 30:452-461. CrossRef Medline

Kolb B, Stewart J (1991) Sex-related differences in dendritic branching of cells in the prefrontal cortex of rats. J Neuroendocrinol 3:95-99. CrossRef Medline

Kornstein SG, Schatzberg AF, Thase ME, Yonkers KA, McCullough JP, Keitner GI, Gelenberg AJ, Ryan CE, Hess AL, Harrison W, Davis SM, Keller MB (2000) Gender differences in chronic major and double depression. J Affect Disord 60:1-11. CrossRef Medline

Likhtik E, Pelletier JG, Popescu AT, Paré D (2006) Identification of basolateral amygdala projection cells and interneurons using extracellular recordings. J Neurophysiol 96:3257-3265. CrossRef Medline

Makkar SR, Zhang SQ, Cranney J (2010) Behavioral and neural analysis of GABA in the acquisition, consolidation, reconsolidation, and extinction of fear memory. Neuropsychopharmacology 35:1625-1652. CrossRef Medline

Marcondes FK, Miguel KJ, Melo LL, Spadari-Bratfisch RC (2001) Estrous cycle influences the response of female rats in the elevated plus-maze test. Physiol Behav 74:435-440. CrossRef Medline

Mareckova K, Holsen LM, Admon R, Makris N, Seidman L, Buka S, Whitfield-Gabrieli S, Goldstein JM (2016) Brain activity and connectivity in response to negative affective stimuli: impact of dysphoric mood and sex across diagnoses. Hum Brain Mapp 37:3733-3744. CrossRef Medline

Maren S (2000) Auditory fear conditioning increases cs-elicited spike firing in lateral amygdala neurons even after extensive overtraining. Eur J Neurosci 12:4047-4054. CrossRef Medline

Maren S, De Oca B, Fanselow MS (1994) Sex differences in hippocampal long-term potentiation (LTP) and pavlovian fear conditioning in rats: positive correlation between LTP and contextual learning. Brain Res 661: 25-34. CrossRef Medline

Markham JA, Juraska JM (2002) Aging and sex influence the anatomy of the rat anterior cingulate cortex. Neurobiol Aging 23:579-588. CrossRef Medline

Markus E, M Z (1997) Sex differences and estrous cycle changes in hippocampus-dependent fear conditioning. Psychobiology 25:246-252.
Marwha D, Halari M, Eliot L (2017) Meta-analysis reveals a lack of sexual dimorphism in human amygdala volume. Neuroimage 147:282-294. CrossRef Medline

Matsuda S, Matsuzawa D, Ishii D, Tomizawa H, Sutoh C, Shimizu E (2015) Sex differences in fear extinction and involvements of extracellular signalregulated kinase (erk). Neurobiol Learn Mem 123:117-124. CrossRef Medline

McDermott CM, Liu D, Ade C, Schrader LA (2015) Estradiol replacement enhances fear memory formation, impairs extinction and reduces comt expression levels in the hippocampus of ovariectomized female mice. Neurobiol Learn Mem 118:167-177. CrossRef Medline

McDonald AJ (1982) Neurons of the lateral and basolateral amygdaloid nuclei: a Golgi study in the rat. J Comp Neurol 212:293-312. CrossRef Medline

McDonald AJ (1985) Immunohistochemical identification of gammaaminobutyric acid-containing neurons in the rat basolateral amygdala. Neurosci Lett 53:203-207. CrossRef Medline

McDonald AJ, Augustine JR (1993) Localization of GABA-like immunoreactivity in the monkey amygdala. Neuroscience 52:281-294. CrossRef Medline

McDonald AJ, Mascagni F (2001) Colocalization of calcium-binding proteins and GABA in neurons of the rat basolateral amygdala. Neuroscience 105:681-693. CrossRef Medline

Mercer KB, Dias B, Shafer D, Maddox SA, Mulle JG, Hu P, Walton J, Ressler KJ (2016) Functional evaluation of a PTSD-associated genetic variant: estradiol regulation and adcyap1r1. Transl Psychiatry 6:e978. CrossRef Medline

Micevych P, Akesson T, Elde R (1988) Distribution of cholecystokininimmunoreactive cell bodies in the male and female rat: II. Bed nucleus of the stria terminalis and amygdala. J Comp Neurol 269:381-391. CrossRef Medline

Milad MR, Igoe SA, Lebron-Milad K, Novales JE (2009) Estrous cycle phase and gonadal hormones influence conditioned fear extinction. Neuroscience 164:887-895. CrossRef Medline

Milad MR, Zeidan MA, Contero A, Pitman RK, Klibanski A, Rauch SL, Goldstein JM (2010) The influence of gonadal hormones on conditioned fear extinction in healthy humans. Neuroscience 168:652-658. CrossRef Medline

Muller JF, Mascagni F, McDonald AJ (2006) Pyramidal cells of the rat basolateral amygdala: synaptology and innervation by parvalbuminimmunoreactive interneurons. J Comp Neurol 494:635-650. CrossRef Medline

Nabekura J, Oomura Y, Minami T, Mizuno Y, Fukuda A (1986) Mechanism of the rapid effect of 17 beta-estradiol on medial amygdala neurons. Science 233:226-228. CrossRef Medline

Nielsen SE, Ahmed I, Cahill L (2013) Sex and menstrual cycle phase at encoding influence emotional memory for gist and detail. Neurobiol Learn Mem 106:56-65. CrossRef Medline

Onishi BK, Xavier GF (2010) Contextual, but not auditory, fear conditioning is disrupted by neurotoxic selective lesion of the basal nucleus of amygdala in rats. Neurobiol Learn Mem 93:165-174. CrossRef Medline

Orsini CA, Kim JH, Knapska E, Maren S (2011) Hippocampal and prefrontal projections to the basal amygdala mediate contextual regulation of fear after extinction. J Neurosci 31:17269-17277. CrossRef Medline

Padival MA, Blume SR, Vantrease JE, Rosenkranz JA (2015) Qualitatively different effect of repeated stress during adolescence on principal neuron morphology across lateral and basal nuclei of the rat amygdala. Neuroscience 291:128-145. CrossRef Medline

Paré D, Collins DR (2000) Neuronal correlates of fear in the lateral amygdala: multiple extracellular recordings in conscious cats. J Neurosci 20:2701-2710. Medline

Park CR, Zoladz PR, Conrad CD, Fleshner M, Diamond DM (2008) Acute predator stress impairs the consolidation and retrieval of hippocampusdependent memory in male and female rats. Learn Mem 15:271-280. CrossRef Medline

Patz S, Grabert J, Gorba T, Wirth MJ, Wahle P (2004) Parvalbumin expression in visual cortical interneurons depends on neuronal activity and trkb ligands during an early period of postnatal development. Cereb Cortex 14:342-351. CrossRef Medline

Paxinos G, Watson C (1998) The rat brain in stereotaxic coordinates (deluxe edition), Ed 4. San Diego, CA: Academic. 
Pelletier JG, Likhtik E, Filali M, Paré D (2005) Lasting increases in basolateral amygdala activity after emotional arousal: implications for facilitated consolidation of emotional memories. Learn Mem 12:96-102. CrossRef Medline

Philpot BD, Lim JH, Brunjes PC (1997) Activity-dependent regulation of calcium-binding proteins in the developing rat olfactory bulb. J Comp Neurol 387:12-26. CrossRef Medline

Polepalli JS, Sullivan RK, Yanagawa Y, Sah P (2010) A specific class of interneuron mediates inhibitory plasticity in the lateral amygdala. J Neurosci 30:14619-14629. CrossRef Medline

Pompili A, Arnone B, D’Amico M, Federico P, Gasbarri A (2016) Evidence of estrogen modulation on memory processes for emotional content in healthy young women. Psychoneuroendocrinology 65:94-101. CrossRef Medline

Protopopescu X, Pan H, Tuescher O, Cloitre M, Goldstein M, Engelien W, Epstein J, Yang Y, Gorman J, LeDoux J, Silbersweig D, Stern E (2005) Differential time courses and specificity of amygdala activity in posttraumatic stress disorder subjects and normal control subjects. Biol Psychiatry 57:464-473. CrossRef Medline

Rademacher DJ, Rosenkranz JA, Morshedi MM, Sullivan EM, Meredith GE (2010) Amphetamine-associated contextual learning is accompanied by structural and functional plasticity in the basolateral amygdala. J Neurosci 30:4676-4686. CrossRef Medline

Radley JJ, Farb CR, He Y, Janssen WG, Rodrigues SM, Johnson LR, Hof PR, LeDoux JE, Morrison JH (2007) Distribution of NMDA and AMPA receptor subunits at thalamo-amygdaloid dendritic spines. Brain Res 1134: 87-94. CrossRef Medline

Rainnie DG, Asprodini EK, Shinnick-Gallagher P (1993) Intracellular recordings from morphologically identified neurons of the basolateral amygdala. J Neurophysiol 69:1350-1362. Medline

Rapkin AJ, Mikacich JA, Moatakef-Imani B, Rasgon N (2002) The clinical nature and formal diagnosis of premenstrual, postpartum, and perimenopausal affective disorders. Curr Psychiatry Rep 4:419-428. CrossRef Medline

Rasia-Filho AA, Fabian C, Rigoti KM, Achaval M (2004) Influence of sex, estrous cycle and motherhood on dendritic spine density in the rat medial amygdala revealed by the Golgi method. Neuroscience 126:839-847. CrossRef Medline

Rey CD, Lipps J, Shansky RM (2014) Dopamine d1 receptor activation rescues extinction impairments in low-estrogen female rats and induces cortical layer-specific activation changes in prefrontal-amygdala circuits. Neuropsychopharmacology 39:1282-1289. CrossRef Medline

Rosenkranz JA, Grace AA (1999) Modulation of basolateral amygdala neuronal firing and afferent drive by dopamine receptor activation in vivo. J Neurosci 19:11027-11039. Medline

Rosenkranz JA, Grace AA (2001) Dopamine attenuates prefrontal cortical suppression of sensory inputs to the basolateral amygdala of rats. J Neurosci 21:4090-4103. Medline

Rosenkranz JA, Grace AA (2002) Cellular mechanisms of infralimbic and prelimbic prefrontal cortical inhibition and dopaminergic modulation of basolateral amygdala neurons in vivo. J Neurosci 22:324337. Medline

Rostkowski AB, Teppen TL, Peterson DA, Urban JH (2009) Cell-specific expression of neuropeptide y y1 receptor immunoreactivity in the rat basolateral amygdala. J Comp Neurol 517:166-176. CrossRef Medline

Rubinow MJ, Drogos LL, Juraska JM (2009) Age-related dendritic hypertrophy and sexual dimorphism in rat basolateral amygdala. Neurobiol Aging 30:137-146. CrossRef Medline

Rudick CN, Woolley CS (2001) Estrogen regulates functional inhibition of hippocampal cal pyramidal cells in the adult female rat. J Neurosci 21: 6532-6543. Medline

Sah P, Faber ES, Lopez De Armentia M, Power J (2003) The amygdaloid complex: anatomy and physiology. Physiol Rev 83:803-834. CrossRef Medline

Sartory G, Cwik J, Knuppertz H, Schürholt B, Lebens M, Seitz RJ, Schulze R (2013) In search of the trauma memory: a meta-analysis of functional neuroimaging studies of symptom provocation in posttraumatic stress disorder (PTSD). PLoS One 8:e58150. CrossRef Medline

Scheibe S, Preuschhof C, Cristi C, Bagby RM (2003) Are there gender differences in major depression and its response to antidepressants? J Affect Disord 75:223-235. CrossRef Medline

Schiess MC, Joëls M, Shinnick-Gallagher P (1988) Estrogen priming affects active membrane properties of medial amygdala neurons. Brain Res 440: 380-385. CrossRef Medline

Schmidt PJ, Rubinow DR (2009) Sex hormones and mood in the perimenopause. Ann N Y Acad Sci 1179:70-85. CrossRef Medline

Sergerie K, Chochol C, Armony JL (2008) The role of the amygdala in emotional processing: a quantitative meta-analysis of functional neuroimaging studies. Neurosci Biobehav Rev 32:811-830. CrossRef Medline

Sheline YI, Barch DM, Donnelly JM, Ollinger JM, Snyder AZ, Mintun MA (2001) Increased amygdala response to masked emotional faces in depressed subjects resolves with antidepressant treatment: an FMRI study. Biol Psychiatry 50:651-658. CrossRef Medline

Sholl DA (1953) Dendritic organization in the neurons of the visual and motor cortices of the cat. J Anat 87:387-406. Medline

Silverstein B (1999) Gender difference in the prevalence of clinical depression: the role played by depression associated with somatic symptoms. Am J Psychiatry 156:480-482. Medline

Spampanato J, Polepalli J, Sah P (2011) Interneurons in the basolateral amygdala. Neuropharmacology 60:765-773. CrossRef Medline

Stevens JS, Hamann S (2012) Sex differences in brain activation to emotional stimuli: a meta-analysis of neuroimaging studies. Neuropsychologia 50:1578-1593. CrossRef Medline

Trouche S, Sasaki JM, Tu T, Reijmers LG (2013) Fear extinction causes target-specific remodeling of perisomatic inhibitory synapses. Neuron 80:1054-1065. CrossRef Medline

Urban JH, Bauer-Dantoin AC, Levine JE (1993) Neuropeptide y gene expression in the arcuate nucleus: sexual dimorphism and modulation by testosterone. Endocrinology 132:139-145. CrossRef Medline

van Veen JF, Jonker BW, van Vliet IM, Zitman FG (2009) The effects of female reproductive hormones in generalized social anxiety disorder. Int J Psychiatry Med 39:283-295. CrossRef Medline

Vesga-López O, Blanco C, Keyes K, Olfson M, Grant BF, Hasin DS (2008) Psychiatric disorders in pregnant and postpartum women in the united states. Arch Gen Psychiatry 65:805-815. CrossRef Medline

Victor TA, Furey ML, Fromm SJ, Ohman A, Drevets WC (2010) Relationship between amygdala responses to masked faces and mood state and treatment in major depressive disorder. Arch Gen Psychiatry 67:11281138. CrossRef Medline

Vlachos I, Herry C, Lüthi A, Aertsen A, Kumar A (2011) Context-dependent encoding of fear and extinction memories in a large-scale network model of the basal amygdala. PLoS Comput Biol 7:e1001104. CrossRef Medline

Waddell J, Bangasser DA, Shors TJ (2008) The basolateral nucleus of the amygdala is necessary to induce the opposing effects of stressful experience on learning in males and females. J Neurosci 28:5290-5294. CrossRef Medline

Washburn MS, Moises HC (1992) Electrophysiological and morphological properties of rat basolateral amygdaloid neurons in vitro. J Neurosci 12: 4066-4079. Medline

Wegerer M, Kerschbaum H, Blechert J, Wilhelm FH (2014) Low levels of estradiol are associated with elevated conditioned responding during fear extinction and with intrusive memories in daily life. Neurobiol Learn Mem 116:145-154. CrossRef Medline

West AR, Grace AA (2000) Striatal nitric oxide signaling regulates the neuronal activity of midbrain dopamine neurons in vivo. J Neurophysiol 83:1796-1808. Medline

Wiltgen BJ, Sanders MJ, Behne NS, Fanselow MS (2001) Sex differences, context preexposure, and the immediate shock deficit in pavlovian context conditioning with mice. Behav Neurosci 115:26-32. CrossRef Medline

Wiltgen BJ, Sanders MJ, Ferguson C, Homanics GE, Fanselow MS (2005) Trace fear conditioning is enhanced in mice lacking the delta subunit of the GABAA receptor. Learn Mem 12:327-333. CrossRef Medline

Wolff SB, Gründemann J, Tovote P, Krabbe S, Jacobson GA, Müller C, Herry C, Ehrlich I, Friedrich RW, Letzkus JJ, Lüthi A (2014) Amygdala interneuron subtypes control fear learning through disinhibition. Nature 509:453-458. CrossRef Medline

Womble MD, Andrew JA, Crook JJ (2002) 17beta-estradiol reduces excitatory postsynaptic potential (EPSP) amplitude in rat basolateral amygdala neurons. Neurosci Lett 331:83-86. CrossRef Medline

Wood GE, Shors TJ (1998) Stress facilitates classical conditioning in males, but impairs classical conditioning in females through activa- 
tional effects of ovarian hormones. Proc Natl Acad Sci U S A 95:40664071. CrossRef

Woodruff AR, Sah P (2007) Networks of parvalbumin-positive interneurons in the basolateral amygdala. J Neurosci 27:553-563. CrossRef Medline

Woolley CS, McEwen BS (1992) Estradiol mediates fluctuation in hippocampal synapse density during the estrous cycle in the adult rat. J Neurosci 12:2549-2554. Medline

Woolley CS, Gould E, Frankfurt M, McEwen BS (1990) Naturally occurring fluctuation in dendritic spine density on adult hippocampal pyramidal neurons. J Neurosci 10:4035-4039. Medline

Wrase J, Klein S, Gruesser SM, Hermann D, Flor H, Mann K, Braus DF, Heinz A (2003) Gender differences in the processing of standardized emotional visual stimuli in humans: a functional magnetic resonance imaging study. Neurosci Lett 348:41-45. CrossRef Medline

Wu Y, Li H, Zhou Y, Yu J, Zhang Y, Song M, Qin W, Yu C, Jiang T (2016)
Sex-specific neural circuits of emotion regulation in the centromedial amygdala. Sci Rep 6:23112. CrossRef Medline

Zeidan MA, Igoe SA, Linnman C, Vitalo A, Levine JB, Klibanski A, Goldstein JM, Milad MR (2011) Estradiol modulates medial prefrontal cortex and amygdala activity during fear extinction in women and female rats. Biol Psychiatry 70:920-927. CrossRef Medline

Zhang W, Rosenkranz JA (2012) Repeated restraint stress increases basolateral amygdala neuronal activity in an age-dependent manner. Neuroscience 226:459-474. CrossRef Medline

Zhang W, Rosenkranz JA (2013) Repeated restraint stress enhances cueelicited conditioned freezing and impairs acquisition of extinction in an age-dependent manner. Behav Brain Res 248:12-24. CrossRef Medline

Zhang W, Rosenkranz JA (2016) Effects of repeated stress on age-dependent GABAergic regulation of the lateral nucleus of the amygdala. Neuropsychopharmacology 41:2309-2323. CrossRef Medline 